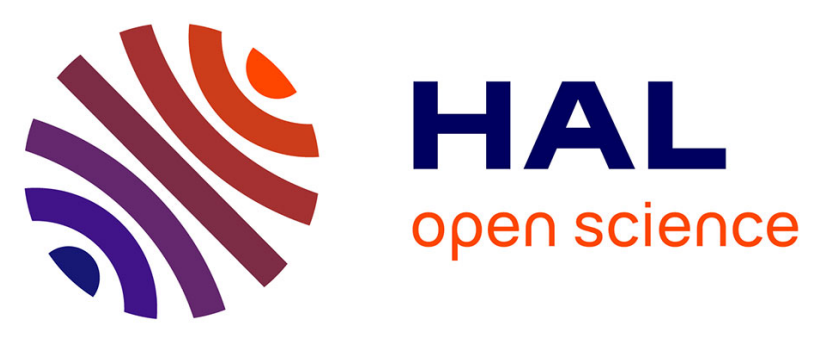

\title{
Disturbances in cholesterol, bile acid and glucose metabolism in peroxisomal 3-ketoacylCoA thiolase B deficient mice fed diets containing high or low saturated fat contents.
}

Valérie Nicolas-Frances, Ségolène Arnauld, Jacques Kaminski, Emiel Ver Loren van Themaat, Marie-Claude Clemencet, Julie Chamouton, Anne Athias, Jacques Grober, Joseph Gresti, Pascal Degrace, et al.

\section{- To cite this version:}

Valérie Nicolas-Frances, Ségolène Arnauld, Jacques Kaminski, Emiel Ver Loren van Themaat, MarieClaude Clemencet, et al.. Disturbances in cholesterol, bile acid and glucose metabolism in peroxisomal 3-ketoacylCoA thiolase B deficient mice fed diets containing high or low saturated fat contents.. Biochimie, 2014, 98, pp.86-101. 10.1016/j.biochi.2013.11.014 . inserm-00912779

\section{HAL Id: inserm-00912779 https://www.hal.inserm.fr/inserm-00912779}

Submitted on 2 Dec 2013

HAL is a multi-disciplinary open access archive for the deposit and dissemination of scientific research documents, whether they are published or not. The documents may come from teaching and research institutions in France or abroad, or from public or private research centers.
L'archive ouverte pluridisciplinaire HAL, est destinée au dépôt et à la diffusion de documents scientifiques de niveau recherche, publiés ou non, émanant des établissements d'enseignement et de recherche français ou étrangers, des laboratoires publics ou privés. 
NICOLAS-FRANCES et al., Altered lipid and glucose metabolism in $T h b^{-/}$mice

1 Disturbances in cholesterol, bile acid and glucose metabolism in peroxisomal contents

\section{Valérie NICOLAS-FRANCES ${ }^{1,2, \dagger}$, Ségolène ARNAULD ${ }^{1,2, \#}$, Jacques KAMINSKI ${ }^{1,2,}$, Emiel Ver LOREN van THEMAAT ${ }^{3}$, Marie-Claude CLEMENCET ${ }^{1,2}$, Julie CHAMOUTON ${ }^{1,2, £}$, Anne ATHIAS ${ }^{4}$, Jacques GROBER ${ }^{6}$, Joseph GRESTI ${ }^{1,5}$, Pascal DEGRACE ${ }^{1,5}$, Laurent LAGROST ${ }^{6}$, Norbert LATRUFFE ${ }^{1,2}$ and Stéphane MANDARD ${ }^{1,2,6 *}$}

${ }^{1}$ INSERM U866, Dijon, 21000, France; ${ }^{2}$ Université de Bourgogne, Faculté des Sciences Gabriel, Equipe 'Biochimie du peroxysome, inflammation et métabolisme lipidique' EA 7270, 21000 Dijon, France; ${ }^{3}$ Max Planck Institute for Plant Breeding Research Carlvon-Linné-Weg 10, 50829 Köln, Germany; ${ }^{4}$ Structure Fédérative de Recherche SantéSTIC, Université de Bourgogne, 21000 Dijon, France; ${ }^{5}$ Université de Bourgogne, Faculté des Sciences Gabriel, Equipe "Physiopathologies des dyslipidémies", 21000 Dijon, France ; ${ }^{6}$ Centre de Recherche INSERM UMR 866 "Lipides, Nutrition, Cancer" - Université de Bourgogne, Equipe "Protéines de transfert des lipides et métabolisme des lipoprotéines", Faculté de Médecine, 21079 Dijon Cedex, France.

†Present address: UMR 1347 Agroécologie AgroSup Dijon/INRA/Université de Bourgogne, Pôle Mécanisme et Gestion des Interactions Plantes-microorganismes - ERL CNRS 6300, 21000 Dijon, France.

£ Present address: INSERM UMR 1069 "Nutrition, Croissance et Cancer", Université François Rabelais, Faculté de Médecine, 10 boulevard Tonnellé, 37032 Tours Cedex, France.

*Corresponding author, present address: Centre de Recherche INSERM UMR 866 "Lipides, Nutrition, Cancer" Université de Bourgogne, Faculté de Médecine, 7 boulevard Jeanne d'Arc, BP 87900, 21079 Dijon Cedex, France. Phone : 33380393266 and Fax : 33380396250. 
E-mail : stephane.mandard@u-bourgogne.fr,

2

3

4

Abbreviations: ThA: 3-ketoacyl-CoA thiolase A; ThB: 3-ketoacyl-CoA thiolase B; FAO: fatty acid oxidation; ACOX1: acyl-coA-oxidase 1; MFP1: peroxisomal multifunctional enzyme type 1; MFP2: peroxisomal multifunctional enzyme type 2; WAT: white adipose tissue; LFD: Low Fat Diet; HFD: High Fat Diet; GH: growth hormone; IGF-I: insulin Growth Factor-I; IGFBP-3: insulin-like growth factor-binding protein-3; PPAR $\alpha$ : peroxisome proliferator-activated receptor alpha; Wy: Wy14,643; WT: wild-type; KO: knock-out; HDL: high density lipoproteins; SR-BI: scavenger receptor class B member 1; SREBP: sterol regulatory element-binding protein; RXR: retinoid $\mathrm{X}$ receptor.

Short title: Altered lipid and glucose metabolism in $T h b^{-/-}$mice

Keywords: peroxisomal 3-ketoacyl-CoA thiolase $\mathrm{B}$, hypoglycemia, de novo biosynthesis of cholesterol, bile acids, lathosterol.

\#

Highlights (Nicolas-Francès et al.,)

"Disturbances in cholesterol, bile acid and glucose metabolism in peroxisomal 3ketoacylCoA thiolase B deficient mice fed diets containing high or low saturated fat contents"

- Reduced body size and plasma growth hormone levels in $T h b^{-/-}$mice

- Higher energy intake but reduced adiposity in $T h b^{-/-}$mice fed a saturated fat diet

- A better insulin sensitivity leads to hypoglycemia in $T h b^{-/}$mice fed synthetic diets

- Increased plasma HDL-cholesterol and whole body cholesterol synthesis in $T h b^{-1-}$ mice

- Increased liver cholesterol content and bile acid synthesis in $T h b^{-/-}$mice 
NICOLAS-FRANCES et al., Altered lipid and glucose metabolism in $T h b^{-/}$mice

2 Abstract

3 The peroxisomal 3-ketoacyl-CoA thiolase B (ThB) catalyzes the thiolytic cleavage of

4 straight chain 3-ketoacyl-CoAs. Up to now, the ability of ThB to interfere with lipid 5 metabolism was studied in mice fed a routinely laboratory chow enriched or not with the 6 synthetic agonist Wy14,643, a pharmacological activator of the nuclear hormone receptor 7 PPAR $\alpha$. The aim of the present study was therefore to determine whether ThB could play a 8 role in obesity and lipid metabolism when mice are chronically fed a synthetic High Fat Diet 9 (HFD) or a Low Fat Diet (LFD) as a control diet. To investigate this possibility, wild-type 10 (WT) mice and mice deficient for Thb $\left(T h b^{-/}\right)$were subjected to either a synthetic LFD or a 11 HFD for 25 weeks, and their responses were compared. First, when fed a normal regulatory laboratory chow, $\mathrm{Thb}^{-/-}$mice displayed growth retardation as well as a severe reduction in the plasma level of growth hormone (GH) and Insulin Growth Factor-I (IGF-I), suggesting alterations in the GH/IGF-1 pathway. When fed the synthetic diets, the corrected energy intake to body mass was significantly higher in $T h b^{-/}$mice, yet those mice were protected from HFD-induced adiposity. Importantly, $T h b^{-/}$mice also suffered from hypoglycemia, exhibited reduction in liver glycogen stores and circulating insulin levels under the LFD and the HFD. Thb deficiency was also associated with higher levels of plasma HDL (High Density Lipoproteins) cholesterol and increased liver content of cholesterol under both the LFD and the HFD. As shown by the plasma lathosterol to cholesterol ratio, a surrogate marker for cholesterol biosynthesis, whole body cholesterol de novo synthesis was increased in $T h b^{-/}$mice. By comparing liver RNA from WT mice and $T h b^{-/}$mice using oligonucleotide microarray and RT-qPCR, a coordinated decrease in the expression of critical cholesterol synthesizing genes and an increased expression of genes involved in bile acid synthesis (Cyp7a Cyp17al, Akrld1) were observed in $T h b^{-/}$mice. In parallel, the 
NICOLAS-FRANCES et al., Altered lipid and glucose metabolism in $T h b^{-/}$mice

1 elevation of the lathosterol to cholesterol ratio as well as the increased expression of

2 cholesterol synthesizing genes were observed in the kidney of $T h b^{-/}$mice fed the LFD and

3 the HFD. Overall, the data indicate that ThB is not fully interchangeable with the thiolase A

4 isoform. The present study also reveals that modulating the expression of the peroxisomal

5 ThB enzyme can largely reverberate not only throughout fatty acid metabolism but also

6 cholesterol, bile acid and glucose metabolism.

7

8

9

10

11

12 
NICOLAS-FRANCES et al., Altered lipid and glucose metabolism in $T h b^{-/-}$mice

\section{1. Introduction}

3 Adipose tissue lipolysis generates free fatty acids that are taken up from the blood plasma by

4 the liver where they are activated into their fatty acyl-CoA derivatives. The activated fatty 5 acyl-CoAs are subsequently imported into mitochondria or peroxisomes for degradation to

6 acetyl-coenzyme A (acetyl-CoA) via the $\beta$-oxidation process. Whereas the mitochondrion

7 oxidizes short-, medium- and mostly long-chain fatty acids, the peroxisome oxidizes some

8 long-chain but mostly very long chain fatty acids. The peroxisome is also involved in the $\alpha-$

9 oxidation of very-long-straight-chain or branched-chain acyl-CoAs (reviewed in [1]). At the biochemical level, the peroxisomal $\beta$-oxidation of straight-chain acyl-CoAs starts with a

11 reaction catalyzed by the ACOX1 (acyl-CoA oxidase 1) enzyme that is the first and rate-

12 limiting enzyme of the pathway. The step orchestrated by ACOX1 is followed by two 13 enzymatic reactions carried out by the MFP1 or MFP2. The fourth and last step of the process is catalyzed by the peroxisomal 3-ketoacyl-CoA thiolases. In humans, only a single corresponding gene (peroxisomal 3-acetyl-CoA acetyltransferase-1 also known as peroxisomal 3-oxoacyl-CoA thiolase or acyl-CoA:acetyl-CoA-acyltransferase, ACAA1, EC 2.3.1.16) has been identified $[2,3]$ and no isolated peroxisomal deficiency at the level of the peroxisomal 3-ketoacyl-CoA thiolase, has not been reported yet $[2,3]$. To date, two closely related but differentially regulated peroxisomal 3-ketoacyl-CoA thiolases isoforms (thiolase

A, ThA, Acaala and thiolase B, ThB, Acaa1b, EC:2.3.1.16) have been identified in rodents $[4,5]$. It is still not clear whether these two proteins stem from a unique and original ancestral gene. In agreement with their very high degree of nucleotide sequence identity (97\%), the mature forms of ThA and ThB differ in only nine amino acid in rats [4-6]. Given the large amino acid sequence identity (96\%) between ThA and ThB, major overlap in the enzymatic activities of ThA and ThB were found [4, 7]. As a consequence, both enzymes 
NICOLAS-FRANCES et al., Altered lipid and glucose metabolism in $T h b^{-/}$mice

1 share virtually the same substrate specificity in vitro that includes very-long-straight-chain

2 3-oxoacyl-CoAs [7]. The cleavage of 2-methyl-branched as well as straight-chain 3-

3 ketoacyl-CoA esters is under the dependence of a third thiolase isoform (SCP-2/3-ketoacyl-

4 CoA thiolase, SCPx) previously characterized in both humans and rodents [8-10].

5 In addition to fatty acid $\beta$-oxidation, the peroxisome is involved in other aspects of lipid

6 metabolism ranging from synthesis of bile acids, plasmalogens, cholesterol and isoprenoids.

7 Consistent with this notion, different studies have shed light on the existence of an

8 alternative pathway for cholesterol synthesis in the peroxisomal matrix, with a specific 3-

9 hydroxy-3-methylglutaryl coenzyme A (HMG-CoA) reductase that displays functional and

10 structural properties different from the endoplasmic reticulum HMG-CoA reductase [11-13].

11 In order to investigate the physiological role of the 3-ketoacylCoA thiolase B (ThB) in vivo,

12 a mouse model deficient for $T h b\left(T h b^{--}\right)$has been partly characterized in our laboratory [14].

13 At the molecular level, Thb was identified as a direct target gene of the peroxisome

14 proliferator-activated receptor alpha (PPAR $\alpha, \mathrm{NR} 1 \mathrm{C} 1)$ in the liver [15]. PPAR $\alpha$ forms a heterodimer with the Retinoid X Receptor (RXR) and following the physical binding of PPAR $\alpha /$ RXR $\alpha$ by the synthetic agonist Wy14,643 (Wy), the mRNA expression of a large arrays of genes ranging from lipid, amino-acid, glycerol and glycogen metabolism as well as 18 inflammation control is upregulated ([16-23]). A crucial piece of evidence that liver Thb is functionally regulated by the nuclear receptor PPAR $\alpha$ is the observation that some hepatic fatty acid contents are different between WT and Thb-/- mice exposed to the PPAR $\alpha$ agonist Wy [21, 24]. Follow-up investigations also revealed that ThB could play an indirect role in the control of PPAR $\alpha$ mediated upregulation of Sterol Regulatory-Element-Binding-Protein2 (SREBP-2) target genes in the liver of mice fed with Wy [25]. This result further 24 demonstrates that the deletion of a single peroxisomal activity such as ThB is sufficient to impact the transcription of biosynthetic cholesterol genes in the liver. Combined, these 
NICOLAS-FRANCES et al., Altered lipid and glucose metabolism in $T h b^{-/}$mice

1 previous data support the notion that despite the similarities between $\mathrm{ThA}$ and $\mathrm{ThB}$, ThB

2 displays a unique biochemical function that deserves further characterization.

3 In addition to be the molecular target of the fibrate drug Wy, PPAR $\alpha$ also mediates the

4 effects of a High Fat Diet (HFD) on hepatic gene expression [26]. As Thb is a PPAR $\alpha$ target

5 gene, we expected that chronic HFD could shed light on the putative consequences of the

6 deletion of Thb in mouse in a more physiological context, i.e. HFD-induced obesity and

7 insulin-resistance.

8 The recent demonstration that resistance to diet-induced obesity is accompanied by a

9 marked increase in peroxisomal $\beta$-oxidation has been instrumental in advancing our

10 thoughts about the origin of oxidative changes during obesity [27, 28]. Using two strains of

11 mice resistant $(\mathrm{A} / \mathrm{J})$ or sensitive $(\mathrm{C} 57 \mathrm{Bl} / 6)$ to diet-induced hepatosteatosis and obesity, it

12 was found that 10 peroxisomal oxidative genes were specifically upregulated in $\mathrm{A} / \mathrm{J}$ mice

13 leading to a significant increase in peroxisomal $\beta$-oxidation [27]. It was thereby

14 hypothesized that this peroxisomal fatty acid $\beta$-oxidation could partly prevent diet-induced

15 hepatosteatosis and obesity.

16 The aim of the present study was therefore to evaluate the role of $\mathrm{ThB}$ and its ability to

17 potentially interfere with HFD-induced lipid metabolism disorders. To explore the function

18 of ThB in this aspect, WT mice and $T h b^{-/}$mice were chronically fed a synthetic High-Fat

19 Diet (HFD) and a Low-Fat Diet (LFD) as control. Our results indicate that Thb deletion in

20 mouse induces alterations not only in fatty acid metabolism but also in carbohydrate,

21 cholesterol and bile acid metabolism, extending the function of ThB to other unexpected

22 metabolic pathways.

\section{Materials and methods}

\subsection{Animal experiments and ethical considerations}


NICOLAS-FRANCES et al., Altered lipid and glucose metabolism in $T h b^{-/}$mice

1 Only male mice on a pure-bred $S v 129$ genetic background have been used and previously

2 described [14]. Male mice were kept in normal cages with food and water ad libitum, unless

3 clearly indicated. In absence of dietary challenge, mice were routinely fed a standard

4 commercial pellet diet (UAR A03-10 pellets from Usine d'Alimentation Rationnelle, Epinay

5 sur Orge, SAFE, France, $3.2 \mathrm{kcal} / \mathrm{g}$ ) consisting (by mass) of about 5.1\% fat (C16:0 \pm 0.89\%;

$6 \mathrm{C} 16: 1 \mathrm{n}-7 \pm 0.09 \% ; \mathrm{C} 18: 0 \pm 0.45 \% ; \mathrm{C} 18: 1 \mathrm{n}-9 \pm 1.06 \%, \mathrm{C} 18: 2 \mathrm{n}-9 \pm 1.53 \%$ and traces of

7 C18:3 n-9), similar to previous studies $[24,25]$. At the time of sacrifice, animals were only

8 7-weeks old. The animal experiments were approved by the animal experimentation

9 committee of the University of Burgundy (protocol number $n^{\circ} 1904$ ) and were performed 10 according to the European Union guidelines for animal care.

\subsection{Nutritional intervention}

Two-month-old male mice were fed with a LFD or a HFD for 25 weeks, as previously described elsewhere [26, 29]. The diets provided either $10 \%$ or $45 \%$ energy (kcal) percent in the form of lard (D12450B or D12451, Research Diets Inc., New Brunswick, NJ, USA). Content in cholesterol was $0,00136 \%(\mathrm{w} / \mathrm{w})$ for D12450B and $0,01489 \%(\mathrm{w} / \mathrm{w})$ for D12451. Table I shows the composition of the diet. At the time of sacrifice, animals were around 7 months of age. Tissues were excised, weighted and immediately frozen in liquid nitrogen before being stocked at $-80^{\circ} \mathrm{C}$. The animal experiments were approved by the animal experimentation committee of the University of Burgundy (protocol $n^{\circ}$ 0107) and were performed according to the European Union guidelines for animal care.

\subsection{Food intake and body size}

Food intake was measured over 3 to 4 days for 25 weeks to the nearest $0.1 \mathrm{~g}$. The 
NICOLAS-FRANCES et al., Altered lipid and glucose metabolism in $T h b^{-/}$mice

1 measurement of body size, animals were lightly anesthetized with $3 \%$ of isoflurane and

2 extended to their maximal length to determine the nose-to-anus distance.

2.4. Histochemistry

Hematoxylin and Eosin staining of adipose sections were done using standard protocols. We kindly acknowledge Amandine Bataille (Plateforme d'Imagerie Cellulaire CellImaP, IFR 100 Santé- STIC, Université de Bourgogne, Dijon, France) for expert technical assistance.

\subsection{Plasma metabolite levels}

10

Plasma was initially collected into EDTA tubes via caudal or retroorbital puncture and centrifuged at $+4^{\circ} \mathrm{C}(10 \mathrm{~min}, 6000 \mathrm{rpm})$. Plasma glycerol concentration was determined using a kit from Instruchemie (Delfzijl, the Netherlands). Plasma free fatty acids were determined using a kit from WAKO Chemicals (WAKO Chemicals, Germany). Plasma glucose concentration was obtained by the enzymatic method employing glucose-oxidase (Glucose GOD FS, Diasys, Diagnostic Systems International, Condom, France). Plasma $\beta$ hydroxybutyrate, cholesterol and triglycerides levels were determined using a kit from Diasys. For lathosterol measurements, plasma or tissue (about 10 to $20 \mathrm{mg}$ of kidney) was mixed with epicoprostanol, which was used as a control standard. Potassium hydroxide saponification was followed by lipid extraction with hexane. Cholesterol and lathosterol were analyzed in the trimethylsilyl ether state by GC-MS using a Hewlett Packard HP6890

Gas Chromatograph equipped with an HP7683 Injector and an HP5973 Mass Selective Detector, as previously described [25].

\subsection{Plasma hormone levels}

26 Plasma growth hormone level was determined using the rat/mouse Growth Hormone ELISA

27 kit from Linco Research (USA). Plasma mouse IGF-1 level was determined using the 
NICOLAS-FRANCES et al., Altered lipid and glucose metabolism in $T h b^{-/}$mice

1 Mouse Insulin-like Growth Factor 1 (IGF-1) ELISA Kit from ASSAYPRO (USA). IGFBP-3

2 serum concentration was measured using the mouse/rat IGFBP-3 ELISA kit provided by

3 BioVendor GmbH (Heidelberg, Germany). Plasma insulin level was evaluated using a

4 mouse insulin enzyme-linked immunosorbent assay kit (Mercodia SA, Sweden).

2.7. Liver fatty acid profile, hepatic triglyceride and bile acid content in the liver

Liver fatty acid profile as well as quantification of hepatic triglyceride content were performed as previously described [24]. Levels of bile acids in the liver were determined by capillary gas chromatography/mass spectrometry as previously reported [30].

10

\subsection{Liver glycogen content}

Hepatic glycogen content was measured using a method that derives from that of Passoneau and Landerdale [31]. Briefly, $100 \mathrm{mg}$ of liver or muscle sample was homogenized in $700 \mu \mathrm{l}$ of $0.4 \mathrm{M} \mathrm{HCLO} 4$ and was centrifuge for $5 \mathrm{~min}$ at $13000 \mathrm{~g} .650 \mu \mathrm{l}$ of the supernatant was then neutralized with $184 \mu \mathrm{l}$ of $0.75 \mathrm{M} \mathrm{K} 2 \mathrm{CO} 3$ and was incubated 10 minutes at $4{ }^{\circ} \mathrm{C}$. After centrifugation, the supernatant fraction $(50 \mu \mathrm{l})$ was diluted in $200 \mu \mathrm{l}$ sodium acetate $0.3 \mathrm{M}$ $(\mathrm{pH} 4.8)$ and incubated in the presence or not of $10 \mathrm{mg} / \mathrm{ml}$ of amyloglucosidase (SigmaAldrich) for $2 \mathrm{~h}$ at $37^{\circ} \mathrm{C}$. The glucose concentration with or without amyloglucosidase treatment was measured using the Glucose-DOD from Diasys. Oyster glycogen type II (Sigma-Aldrich) was similarly treated and used as standard.

\subsection{RNA isolation and Real-time quantitative PCR (RTqPCR)}

Total RNA was extracted from liver with TRIzol (Invitrogen) using the supplier's instructions. RNA was then further purified (from free nucleotides and contaminating genomic DNA) using RNeasy columns (Qiagen) with DNAse treatment. A $260 \mathrm{~nm} / 280 \mathrm{~nm}$ ratio of $\sim 2$ indicated that samples were essentially free from contaminants such as protein. 
NICOLAS-FRANCES et al., Altered lipid and glucose metabolism in $T h b^{-/}$mice

1 The reverse-transcription step was subsequently performed with $1 \mu \mathrm{g}$ of RNA using iScript

2 Reverse Transcriptase (Bio-Rad). PCR reactions were performed using the qPCR

3 MasterMix Plus for SYBR Green I with fluorescein (Eurogentec) using an iCycler PCR

4 machine (Bio-Rad). Primers were designated to generate a PCR amplification product of

$5 \quad 100-200$ bp and were selected according to indications provided by the Primer 3 software

6 (http://frodo.wi.mit.edu/cgi-bin/primer3/primer3_www.cgi). Sequences are available from

7 S.M. on request. Specificity of the amplification, evaluation of primer dimers formation and

8 efficiency of PCR amplification were verified by melt curve analysis. The "delta-delta Ct"

9 quantification method was used and the expression of each tested gene was related to the

10 control gene 36B4, which did not change under any of the experimental conditions studied.

\subsection{Preparation of nuclear extracts of kidney and immunoblot analysis}

Nuclear extracts of kidney were prepared following established protocols [32]. $10 \mu \mathrm{g}$ of nuclear protein was separated on a $10 \%(\mathrm{w} / \mathrm{v})$ polyacrylamide gel in the presence of $0.1 \%$ (w/v) SDS and transferred on to PVDF membranes. A broad range pre-stained SDS-PAGE standard (Bio-Rad, 161-0318) was used as a protein ladder. After membrane saturation at room temperature for 90 min with TBS $(0.1 \mathrm{M}$ Tris/HCl, $\mathrm{pH} 8.0,0.15 \mathrm{M} \mathrm{NaCl})$ containing $0.1 \%(\mathrm{v} / \mathrm{v})$ Tween 20 and $5 \%(\mathrm{w} / \mathrm{v})$ fat-free milk, blots were incubated overnight at $4{ }^{\circ} \mathrm{C}$ with a polyclonal anti-SREBP-2 rabbit antibody (Ab28482, 1:200, Abcam) or a polyclonal sheep antibody to histone H1 (Ab1938, 1:200, Abcam), respectively. After three washes in TBS containing $0.1 \%(\mathrm{v} / \mathrm{v})$ Tween 20 , primary antibodies were detected using a peroxidaseconjugated IgG antibody, the choice of which depends on the primary antibody of interest: a goat anti-rabbit IgG Antibody, (1:30000, sc-2004, Santa Cruz Biotechnology) or a rabbit anti-sheep IgG antibody (Ab6747, 1:2000, Abcam). The protein bands labeled with the antibodies were visualized using a Western-blotting chemiluminescence luminol reagent 
NICOLAS-FRANCES et al., Altered lipid and glucose metabolism in $T h b^{-/}$mice

1 (Santa Cruz Biotechnology) by exposure to X-ray films (Amersham). Densitometry of

2 proteins on Western blots was performed using the Scion Image software.

3

4

5

6

7

\subsection{Lipoprotein profiling}

Individual mouse plasma from WT $(\mathrm{n}=12)$ or $T h b^{-/}(\mathrm{n}=8)$ mice fed the LFD or the HFD (WT, $\mathrm{n}=11$ and $T h b^{-/}, \mathrm{n}=10$ ) was injected onto a Superose 6HR 10/30 column (Amersham Biosciences) connected to a fast protein liquid chromatography (FPLC) system (Amersham Biosciences). Lipoproteins were eluted at a constant $0.3 \mathrm{ml} / \mathrm{min}$ flow rate with Tris-buffer saline containing $0.074 \%$ EDTA and $0.02 \%$ sodium azide. Total cholesterol and triglyceride levels were determined in the different fractions using commercially available kits from Diasys (Diagnostic Systems International, Condom, France).

\subsection{DNA microarray/transcriptional profiling}

The transcriptional profiles in liver from 7-month-old WT mice and $T h b^{-/-}$mice fed either the LFD or the HFD for 5 months (mice were fasted $6 \mathrm{~h}$ before sacrifice) were probed using the whole genome Affymetrix GeneChip ${ }^{\circledR}$ Mouse Genome 4302.0 Array. For each condition, livers from 4 different mice were used, and the liver RNAs were further isolated but importantly not pooled. Hybridizations (4 per condition), washing and scanning of the chips were carried out at the MicroArray Facility in Leuven (MAF, Leuven, Belgium). The rest of the procedure was performed as previously described [33].

\subsection{Statistical analyses}

Data are presented as means \pm standard errors. The effect of the genotype (KO vs WT) was tested using the Student's t-test. The cut-off for statistical significance was set at a p-value of 
NICOLAS-FRANCES et al., Altered lipid and glucose metabolism in $T h b^{-/}$mice

1 0.05. Area under Curve was calculated with Prism (GraphPad Software Inc., Version 3.0,

2 San Diego, CA, USA).

3

4

5

\section{Results}

6 3.1 Post-natal growth restriction and alteration of the GH/IGF-1 axis in Thb $^{-/-}$mice

7 The generation of mice deficient for $T h b$ has been previously described elsewhere [14]. In

8 absence of any dietary challenge (normal laboratory chow), the most apparent phenotype of

$9 \quad \mathrm{Thb}^{-/-}$mice was their reduced body mass (Fig. 1a) and reduced body length (Fig. 1b) as soon

10 as 4 weeks of age onwards, suggesting post-natal growth restriction. Growth hormone (GH)

11 as released by the pituitary is essential for normal growth and development. Of note,

12 deletion of $T h b$ severely decreased GH circulating levels in 7-weeks-old mice supporting the

13 hypothesis of alterations in the hypothalamo-pituitary axis (Fig. 1c). Most of the effects of

14 GH are exerted by IGF-I, (Insulin-like Growth Factor-I also known as somatomedin C) a

15 peptide hormone produced mainly by the liver but also locally by specific tissues [34, 35].

16 Systemic levels of IGF-I were significantly reduced in 7-weeks-old $T h b^{-/-}$mice compared to

17 age-matched controls (Fig. 1d). The biodisponibility of IGF-I is regulated by specific

18 binding proteins (IGFBP), insulin-like growth factor-binding protein-3 (IGFBP-3) being the

most abundant IGFBP in circulation that binds the majority $(\approx 90 \%)$ of circulating IGF-I

20 [36]. Plasma IGFBP-3 concentrations were similar in 7-weeks-old WT mice and $T h b^{-/}$mice

21 indicating that reduced IGF-I content by change in plasma IGFBP-3 concentrations is

22 unlikely and cannot account for the small-body phenotype observed in $T h b^{-/}$mice (Fig. 1e).

23 Liver is responsible for at least $75 \%$ of the circulating IGF-I levels [34]. Therefore, we

24 checked for hepatic Igf-I mRNA levels in 7-weeks-old WT mice and $T h b^{-/-}$mice. Our results 
NICOLAS-FRANCES et al., Altered lipid and glucose metabolism in $T h b^{-/}$mice

1 indicated that $I g f-1$ mRNA in liver showed a similar pattern to plasma IGF-I in $T h b^{-/}$mice,

2 as a probable consequence of the reduced stimulation by GH (Fig. 1f). GH-dependent

3 stimulation of Igf-I expression also takes place in peripheral tissues among which adipose

4 tissue and skeletal muscle. Similar to the liver, it was found that brown adipose tissue and

5 white adipose tissue as well as muscle Igf-1 mRNA levels were severely reduced in 7-

6 weeks-old $T h b^{-/-}$mice, suggesting that the peripheral production of IGF-1 was globally

7 impaired by the deletion of Thb (Fig. 1f). Together, it was concluded that $T h b^{-/}$mice exhibit

8 early growth retardation due to a probable alteration of the GH/IGF-I axis.

\section{2 $\mathrm{Thb}^{-/}$mice are protected from HFD-induced adipocyte hypertrophy}

11 Chronic administration of a HFD is known to induce obesity and obesity-associated insulin 12 resistance in mice [37]. We therefore decided to study the role that ThB may play in dietinduced obesity by placing wild-type (WT) and $T h b^{-/-}$males, at 2 months of age, on either a synthetic control LFD (10\% fat, D12450B, Research Diets, Inc.) or a synthetic high (saturated-lard) fat diet (45\% fat, D12451, Research Diets, Inc.) for 25 weeks (see Table I for the composition). D12450B and D12451 diets have been extensively used with success in previous metabolic studies [29, 38, 39]. First, detailed analysis of food intake was assessed throughout the period of the diet intervention. Surprisingly, food intake (g) and consequently energy intake (Kcal) were significantly reduced in $T h b^{-/}$mice compared to WT mice after the HFD (supplemental Fig. 1a and supplemental Fig. 1b). However, when energy consumption was corrected for body mass, it becomes significantly higher in $T h b^{-/}$mice fed the LFD or the HFD, as compared to appropriate WT control mice, suggesting that the differences observed in body mass between the 2 sets of mice may not be attributable to decreased energy consumption (supplemental Fig. 1c). Furthermore, while feeding the HFD caused a significant mass gain in WT mice, the effect was less evident in $T h b^{-/-}$mice (Fig. 
NICOLAS-FRANCES et al., Altered lipid and glucose metabolism in $T h b^{-/}$mice

1 2a). Area under the curve (for the evolution of the body mass throughout the diet

2 intervention) confirmed that body mass of $T h b^{-/-}$mice was smaller compared to WT control

3 mice, whatever the quality of the food (Fig. 2b). We also assessed body mass at the end of

4 the diet intervention (Fig. 2c). It was confirmed that $T h b^{-/}$mice did not recover from their

5 initial reduced body mass. Then, we turned to the study of the overall body mass change

6 (expressed in \% of the initial body mass) (Fig. 2d). HFD feeding caused significantly more

7 body mass gain compared with LFD feeding in WT mice and while not significant $(\mathrm{p}=0,07)$,

$8 T h b^{-/}$mice tend to be protected from HFD-induced mass gain.

9 After 25 weeks of diet intervention, significant effects for the diet but also of the genotype

10 were observed for the weight of subcutaneous (Fig. 3a; expressed as a percentage of total

11 body weight) and epididymal fat pads (Fig. 3b), two fat depots that are assumed to reflect

12 the overall adiposity of the animals [40]. Of note, deletion of Thb had no impact on the relative brown adipose tissue weight (Fig. 3b). A histological analysis of the reproductive white adipose tissue (WAT) between WT mice and $T h b^{-/}$mice revealed a reduction in adipocyte size in $T h b^{-/}$mice, fed the LFD or the HFD (Fig. 3c). Further analysis of the adipose tissue morphology using image analysis confirmed this reduction in adipocyte size in $T h b^{-/}$mice and consistently, demonstrates the presence of hyperplasia (Fig. 3d). To uncover the potential systemic manifestations of reduced adiposity in $T h b^{-/}$mice, we measured two different plasma lipid parameters (free fatty acids and glycerol are good indicators of adipose spontaneous lipolysis) in WT mice and $T h b^{-/-}$mice. No significant changes in plasma free fatty acids and glycerol content were observed between WT mice and $T h b^{-/-}$mice indicating that spontaneous lipolysis is likely not exacerbated by the deletion of $T h b$ and cannot account for by the reduced adipose tissue mass (Fig. 3e and 3f). Together,

24 we concluded that $T h b^{-/}$mice are smaller than WT counterparts, while they ingest more 25 calories and display adipose hyperplasia. 
NICOLAS-FRANCES et al., Altered lipid and glucose metabolism in $T h b^{-/}$mice

\section{$2 \quad 3.3$ Thb $^{-/-}$mice display better insulin sensitivity and hypoglycemia}

3 It is known that small adipocytes are more insulin-sensitive than large adipocytes and

4 therefore, they may augment glucose transport and whole body sensitivity [41, 42]. Hence,

5 reduction in the adipocyte size, as observed in $T h b^{-/}$mice fed the LFD or the HFD, could

6 limit the HFD-induced insulin resistance, as demonstrated in several animal models of diet-

7 induced obesity [43]. To test whether insulin sensitivity was indeed better in $T h b^{-/-}$mice, we

8 performed an insulin tolerance test (ITT) in WT mice and $T h b^{-/}$mice fed the LFD or the

9 HFD. In mice fed the LFD, an i.p. insulin challenge ( 0.75 unit per kilogram of body weight)

10 resulted in a similar blood glucose decrease (Fig. 4a). However, in mice fed the HFD,

11 insulin injection resulted in a more prominent blood glucose decrease in $T h b^{-/}$mice

12 compared to WT mice, indicating that $T h b^{-/}$mice are more sensitive to exogenous insulin.

13 Area-under-the-curve (AUC) values confirmed a significantly better preserved insulin

14 sensitivity of $T h b^{-/}$mice on the HFD compared to WT mice (Fig. 4b).

15 We next determined whether glucose metabolism could be altered along with fat deposition 16 in $T h b^{-/}$mice. To do so, we first evaluated circulating blood glucose levels in $T h b^{-/-}$mice.

17 Surprisingly and despite their higher relative energy intake compared to bodyweight, a significant lower plasma glucose concentration was observed in fed or in short-term $(5 \mathrm{~h})$ fasted $T h b^{-/}$mice, independently of the quality of the food (Fig. 4c and Fig. 4d). Following $18 \mathrm{~h}$ and $24 \mathrm{~h}$ of fasting, no differences were observed in plasma glucose levels between WT

21 mice and $\mathrm{Thb}^{-/-}$mice suggesting that neoglucogenesis (a biological process that mainly 22 operates in the liver under fasting conditions and that describes the conversion of noncarbohydrates such as glycerol, propionate, lactate and pyruvate into glucose) becomes similarly active in both genotypes (Fig. 4d). 
NICOLAS-FRANCES et al., Altered lipid and glucose metabolism in $T h b^{-/}$mice

1 Taking into account the massive hypoglycaemia observed in $T h b^{-1}$ mice, it can be

2 hypothesized that $\mathrm{Thb}^{-/-}$mice are more insulin sensitive, as also suggested by the data of Fig.

34 a. In agreement with this notion, endogenous plasma insulin levels were consistently lower

4 in $T h b^{-/}$mice compared with WT mice, under both the LFD and the HFD (Fig. 4e). Finally,

5 the insulin-mediated glucose uptake by the muscle is probably more efficient in $T h b^{-/}$mice

6 than in WT mice because glycogen content of muscle was higher in $T h b^{-/-}$mice than in WT

7 mice (Fig. 4f). Overall, $T h b^{-/}$mice appeared to be more insulin sensitive because they

8 maintained lower glucose concentrations with reduced amounts of insulin.

9 Hepatic glycogenolysis normally sustains blood glucose levels after short-term fasting.

10 Defective glycogenolysis and/or depletion of the initial glycogen stores in the liver of $T h b^{-/}$

11 mice could lead to hypoglycemia. To determine if the absence of Thb also modify glycogen

12 metabolism in the liver, we evaluated the concentration of hepatic glycogen in WT mice and

$13 T h b^{-/}$mice. It is of note that hepatic glycogen content was significantly reduced following

14 the disabling of $T h b$ (Fig. 5a). Reduced concentration of glycogen in the liver of $T h b^{-/}$mice

15 could reflect a marked reduction in the glycogen synthesis rate by the liver. A defect in the

16 mRNA expression level of Glycogen synthase 2 (Gys2), the rate-limiting enzyme for

17 glycogen synthesis in liver, is unlikely because RT-qPCR and DNA arrays demonstrated that Gys2 expression tend to be higher in $T h b^{-1-}$ mice, although it did not reach statistical significance (Fig. 5b). On the other hand, glycogen utilization could be theoretically enhanced by Thb deletion and account for by the reduced glycogen content. Yet, the mRNA expression of genes encoding critical enzymes for glycogen utilisation (Gbe1, Gaa) was lower in $\mathrm{Thb}^{-/}$mice and therefore does not support this hypothesis (supplemental Table). Overall, it was concluded that peroxisomal ThB is involved in carbohydrate metabolism because circulating glucose levels as well as liver/muscle glycogen content are affected when $T h b$ is deleted. 
NICOLAS-FRANCES et al., Altered lipid and glucose metabolism in $T h b^{-/}$mice

\section{$2 \quad 3.4 \mathrm{Thb}^{-/-}$mice do not develop HFD-induced liver steatosis}

3 Consistent with the notion that the peroxisomal ThB is primarily an oxidative enzyme,

4 recent evidence suggests that ThB plays a functional role in fatty acid pattern of total liver

5 lipids, especially when mice are metabolically challenged with the potent PPAR $\alpha$ agonist

6 Wy14,643 [24]. Therefore, it can be expected that the effects of Thb deletion become much

7 more severe under conditions of fat overload such as chronic high fat feeding, a

8 physiological condition that activates PPAR $\alpha$ and PPAR $\alpha$ signaling in liver [26]. The liver

9 is a critical organ that may indirectly contribute to the reduced adiposity observed in $T h b^{-/-}$

10 mice via increased peroxisomal and/or mitochondrial fatty acid $\beta$-oxidation (FAO).

11 Quantitative assays were therefore conducted with liver samples of WT mice and $T h b^{-/}$mice

12 in order to evaluate the impact of $T h b$ deletion on triglyceride content. As expected, HFD

13 significantly increased hepatic lipid storage in WT mice (supplemental Fig. 1a). Regarding

$14 \mathrm{Thb}^{-/-}$mice, liver triglyceride content was also increased by the HFD to a further extent compared to WT mice, yet the effect was not significantly different $(\mathrm{p}=0.07)$. The definitive evidence that ThB was required for the maximal rate of peroxisomal fatty acid $\beta$-oxidation came with the finding that the content of docosanoic acid (C22:0), tetracosanoic acid (C24:0) and possibly hexacosanoic acid (C26:0) was higher in liver samples of $\mathrm{Thb}^{-/-}$mice (supplemental Figure 1b). Together, these data fit with the notion that ThB plays a functional role in lipid handling.

3.5 $\mathrm{Thb}^{-/-}$mice display increased plasma HDL-cholesterol (HDL-c) levels together with higher liver cholesterol content

24 To go further into the analysis of the Thb deficient mouse model, other plasma lipid parameters were assessed. Whatever the genotype and the feeding status, no significant 
NICOLAS-FRANCES et al., Altered lipid and glucose metabolism in $T h b^{-/}$mice

1 changes in circulating TG were found (Fig. 6a). In contrast, total cholesterol content was

2 markedly elevated in the plasma of $T h b^{-/}$mice, fed the LFD or the HFD (Fig. 6d). Profiling

3 of lipoproteins using Fast Protein Liquid Chromatography analysis confirmed that plasma

4 TG was only modestly affected by the deletion of Thb (Fig. 6b and 6c). Lipoprotein profiles

5 obtained from animal fed the LFD or the HFD demonstrated that the plasma cholesterol was

6 found almost entirely as HDL (High Density Lipoproteins) cholesterol (HDL-c) in both

7 genotypes (Fig. 6d). In agreement, the increase in total plasma cholesterol previously

8 observed in $T h b^{--}$mice was exclusively attributable to the HDL fractions (Fig. 6e and 6f).

9 In mammals, the liver plays a critical role in lipoprotein cholesterol metabolism and

10 hepatocytes can acquire cholesterol via the scavenger receptor class B, type I (SR-BI), that

11 mediates the selective cholesterol uptake from HDL. Consistent with cholesterol enrichment

12 of HDL particles that transport excess cholesterol from peripheral tissues back to the liver,

13 the hepatic cholesterol content was significantly elevated in the liver of $T h b^{-/}$mice,

14 especially under the HFD (Fig. 7a). These findings support the notion that ThB may play an

15 unexpected and indirect role in reverse cholesterol transport, and overall in cholesterol

16 homeostasis.

\subsection{Whole body cholesterol de novo biosynthesis is increased in $\mathrm{Thb}^{-/-}$mice}

It is worth noting that some authors have reported that plasma HDL-cholesterol would be related to cholesterol synthesis markers [44]. Furthermore, cumulative evidence in the literature points to a functional role of the peroxisome in cholesterol metabolism, which is consistent with the fact that part of the isoprenoid pathway is localized within the peroxisomal matrix $[11,25,33,45-49]$. Therefore, to further establish without any ambiguity that ThB plays a functional in cholesterol homeostasis in mice, we evaluated 
NICOLAS-FRANCES et al., Altered lipid and glucose metabolism in $T h b^{-/}$mice

1 for global cholesterol synthesis, because it correlates well with the cholesterol balance [50-

2 52]. Unlike cholesterol, the pool of lathosterol is small and turns over rapidly, making

3 lathosterol an analyte of choice [53]. As shown in Fig. 7b, lathosterol concentration and

4 lathosterol to cholesterol ratio were significantly elevated in plasma samples of $T h b^{-/}$mice

5 fed either the LFD or the HFD, indicating enhanced whole body cholesterol biosynthesis.

$7 \quad 3.7$ De novo cholesterol biosynthesis in liver and intestine cannot account for by the 8 elevated cholesterol concentration in the plasma of $\mathrm{Thb}^{-/-}$mice.

9 Liver and small intestine are major organs for cholesterol homeostasis and HDL-cholesterol metabolism. In the mouse, Thb is expressed at a much higher level in liver than in intestine where mRNAs for Thb are barely detectable $[4,15]$. We therefore first examined hepatic cholesterol metabolism in WT mice and $T h b^{-/}$mice, fed either the LFD or the HFD. Increased hepatic content of cholesterol in $T h b^{-/}$mice could be normally associated with reduced expression of cholesterol metabolism associated genes, as a common negative feedback process. To verify whether this was the case, we used RT-qPCR to quantify the steady-state expression level of two highly critical genes for cholesterol biosynthesis, i.e. Hmg-CoA synthase and Hmg-CoA reductase (the rate-limiting enzyme in cholesterol biosynthesis) in the liver of WT mice and $T h b^{-/}$mice fed the LFD or the HFD. Even if it did not reach statistical significance, the absence of Thb tend to decrease the mRNA levels of Hmg-CoA synthase (Fig. 7c). In parallel, the deletion of Thb had no consequence on the mRNA levels of Hmg-CoA reductase and HFD induced a similar decrease in hepatic HmgCoA reductase mRNA levels (Fig. 7c). Western blotting experiment confirmed this observation at the level of HMG-CoA reductase protein (data not shown). Importantly, the mRNA levels of downstream genes of $\mathrm{Hmg-CoA}$ synthase and $\mathrm{Hmg}-\mathrm{CoA}$ reductase such as 
NICOLAS-FRANCES et al., Altered lipid and glucose metabolism in $T h b^{-/}$mice

$1 S c 5 d, D h c r 7, N s d h l$ (lanosterol pathway) were all coordinately decreased in the liver of $T h b$

$2^{1}$ mice fed the LFD (supplemental table and data not shown). Because the HFD per se

3 strongly decreases the mRNA levels of the abovementioned genes, we failed to observe

4 exacerbated decrease of this array of genes in $T h b^{-/}$mice fed this particular regimen,

5 compared to WT control mice (supplemental table and data not shown). Last, the hepatic

6 mRNA expression level of Srebp2, the transcription factor regulating the cholesterol

7 biosynthesis pathway, was also decreased in $T h b^{-/}$mice fed the LFD.

8 While this is not a definitive proof, the gene expression analysis observed here globally

9 supports the hypothesis that cholesterol biosynthesis in the liver probably does not

10 massively account for by the elevated cholesterol concentration in the plasma of $T h b^{-/-}$mice.

11 As previously recall, the small intestine is an important site for the synthesis and secretion of

12 the Apo-AI protein, the principal apoprotein of HDL. In agreement, about $50 \%$ of total plasma Apo-AI protein comes from the intestine [54]. Therefore, in view of the elevated plasma HDL cholesterol levels observed in $T h b^{-/}$mice, it could be reasoned that this metabolism is modulated in the small intestine. However, RT-qPCR experiments do not support this hypothesis because none of the following genes (Abcal, Apo-aI, Apo-aII, Sr-bI) were dysregulated by the deletion of Thb (data not shown). The same was also true for the jejunal expression of $\mathrm{Hmg-CoA}$ synthase, Hmg-CoA reductase, Abcg5 and Abcg8 genes suggesting that elevated jejunal de novo biosynthesis of cholesterol cannot account for by the elevated whole body cholesterol metabolism observed in $T h b^{-/}$mice (data not shown).

3.8 $\mathrm{Thb}^{-/-}$mice display increased mRNA levels of some bile acid synthesizing genes as well as elevated content of some bile acids

24 Excess cholesterol can be toxic in the liver where it may contribute to non-alcoholic fatty 25 liver disease. As part of the physiologic response to the relative cholesterol enrichment 
NICOLAS-FRANCES et al., Altered lipid and glucose metabolism in $T h b^{-/}$mice

1 observed in the liver of $T h b^{-/}$mice, mRNA expression levels of Cyp7al (cytochrome P450,

2 family 7, subfamily A, polypeptide 1; CYP7A1 is the rate limiting step in the classical

3 pathway of bile acid biosynthesis), Cyp39al (cytochrome P450, family 39, subfamily A,

4 polypeptide 1; CYP39A1 is involved in bile acid hydroxylation) and Akrldl (aldo-keto

5 reductase, family 1, member $d 1$; AKR1D1 has a crucial role in synthesis of primary bile

6 acids) were significantly higher in the livers of $T h b^{-/}$mice fed the LFD or the HFD (Fig.

7 7d). Hence, synthesis and perhaps secretion of bile acids, which constitutes a major route for

8 elimination of excess cholesterol from the liver, might be increased in the liver of $T h b^{-/-}$

9 mice. To verify whether this up-regulation of mRNA levels of bile acid synthesizing genes

10 was functionally translated, the content of some bile acid species in mice was evaluated in

11 WT and $T h b^{--}$mice. As illustrated Fig.7e, deletion of $T h b$ was associated with a significant

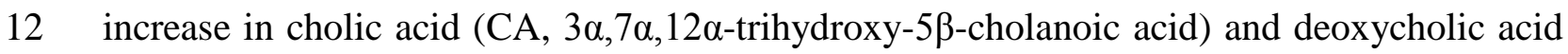

13 ((DCA, $(3 \alpha, 5 \beta, 12 \alpha, 20 R)-3,12$ - dihydroxycholan- 24- oic acid)) when mice are fed the

14 LFD, suggesting the increased conversion of cholesterol into bile acids. The same picture

15 was also present under the HFD but did not reach statistical significance. The gene 16 expression level of Abcg5 and Abcg8 (Abcg: ATP-binding cassette, subfamily G; two ABC

17 half-transporters that work cooperatively in the biliary excretion of sterols into the 18 canaliculus) was significantly increased in hepatic samples of $T h b^{-/-}$mice compared to WT

19 control mice (Fig. 7f and supplemental table).

20 Together, these findings support the concept of a compensatory hepatic up-regulation of bile 21 acid synthesizing enzymes as well as of transporters (that mediate active efflux of 22 cholesterol) in the liver of $T h b^{-/-}$mice.

\subsection{Cholesterol de novo biosynthesis is increased in the kidney of $\mathrm{Thb}^{-/-}$mice}


NICOLAS-FRANCES et al., Altered lipid and glucose metabolism in $T h b^{-/}$mice

1 Given that in addition to the liver, peroxisomes are abundantly present in the kidney where

2 both the Thb gene is well expressed and the ThB protein localized, we sought for evidence

3 that cholesterol de novo biosynthesis could be increased in the kidney of $T h b^{--}$mice $[4,55]$.

4 Importantly, lathosterol content and lathosterol to cholesterol ratio were significantly 5 elevated in kidney samples of $T h b^{-/}$mice, indicating enhanced in situ cholesterol 6 biosynthesis (Fig. 8a and Fig. 8b). However, renal cholesterol content was not different 7 between the two genotypes (Fig. 8c). This last observation suggests that excess production

8 of cholesterol by the kidney in $T h b^{--}$mice may be directly delivered into the bloodstream,

9 where it could perhaps be further associated with circulating HDL lipoproteins. The increase 10 in renal lathosterol to cholesterol ratio observed in $T h b^{-/-}$mice was supported by the parallel 11 increase expression of Hmg-CoA synthase, Fdpps and Srebp2 in the kidney (Fig. 8d). 12 Finally, western-blotting experiment confirmed the enrichment in the nuclear and active form of the transcription factor SREBP-2, a master transcriptional regulator of cholesterol 14 biosynthetic genes (Fig. 8e).

15

16

\section{Discussion}

It was previously reported that peroxisomal $\beta$-oxidation of fat was enhanced during the course of diet-induced obesity [27, 28]. The authors have proposed that elevated peroxisomal $\beta$-oxidation would contribute to the resistance of diet-induced hepatic steatosis and obesity. In light of this finding, the initial goal of this study was to evaluate the consequences of Thb deletion in mice chronically fed a HFD. Unexpectedly, our data first establish a critical role for ThB in the control of body growth, under baseline conditions. The reduced body mass and size probably account for by the marked reduction in the circulating levels of GH and IGF-I in 7-weeks-old $T h b^{-/}$mice, because circulating levels of IGF-1 regulate bone growth and density [56]. Further studies using dual-emission X-ray 
NICOLAS-FRANCES et al., Altered lipid and glucose metabolism in $T h b^{-/}$mice

1 absorptiometry (DEXA)-scan analysis of whole-body are deserved to assess for potential 2 changes in bone mineral content, bone density and bone size in $T h b^{-/}$mice. Altered 3 biodisponibility of the remaining $66 \%$ IGF-I in 7-weeks-old $T h b^{-/-}$mice is unlikely because

4 circulating IGFBP-3 levels and liver Igfbp-3 mRNA levels were unaltered (data not shown).

5 Here, it should be acknowledged that the deletion of the closely related gene Scpx thiolase

6 did not reveal any body growth impairment [8]. However, post-natal growth retardation has

7 been previously reported for other mouse models deficient for the peroxisomal enzymes

8 such as ACOX1 and MFP2 $[57,58]$. The mechanism of body growth retardation in Acox $1^{-/-}$

9 and $\mathrm{Mfp}^{-\mathrm{I}^{-}}$mutant mice remains largely speculative and was not elucidated at the moment.

10 Therefore, one of the future challenges will be to delineate the exact cause(s) responsible for 11 the body growth restriction observed in $T h b^{-/}$mice. Also more extensive analyses that aim 12 at determining if the systemic infusion of recombinant GH or IGF-I could correct the 13 defective growth of $T h b^{-/}$mice have to be envisioned. It should be acknowledged here that

14 the reduction of global body weight in $T h b^{-/}$mice is probably not due to a reduction in 15 energy intake because corrected energy intake to body mass is higher in $T h b^{-/}$mice fed the LFD or the HFD. However, we cannot rule out at this point that growth retardation is caused

17 by intestine malabsorption.

Strikingly, our studies indicate that $T h b^{-/}$mice are protected from HFD-induced expansion of epididymal adipose tissue, the most commonly used fat depot in mouse studies, which likely reflects differences in overall adiposity [40]. An important question is why there is an apparent limit to the expansion of adipose tissue in $T h b^{-/}$mice fed the HFD, despite increased (corrected) energy intake. Total body composition analysis by quantitative nuclear magnetic resonance and determination of whole body metabolic activity as well as fuel 24 preference should provide the first clues. It is also conceivable that the reduced adiposity in $25 T h b^{-/}$mice stems from increased energy expenditure arising from physical activity or 
NICOLAS-FRANCES et al., Altered lipid and glucose metabolism in $T h b^{-/}$mice

1 changes in the ratio between lipogenesis and lipolysis/ $\beta$-oxidation. It is also possible that the

2 mobilization of fat stores, which occurs predominantly through the hydrolysis of

3 triglycerides into glycerol and fatty acids, is increased in $T h b^{-/}$mice. However, this latter

4 hypothesis is unlikely because plasma free fatty acids and glycerol levels were not

5 differently affected by the deletion of Thb (figure 9).

6 Our results also support the notion that ThB is involved in glucose homeostasis because $T h b^{-}$

$7^{1-}$ mice fed either the LFD or the HFD display hypoglycaemia in fed and after a short-term

8 (5h) fasting period. This finding is exciting because i) this is the first report showing that a

9 peroxisomal defect in mice is associated with a marked hypoglycemia that takes place not

10 only after a short-term food deprivation but also in the fed state, ii) it definitively provides

11 evidence that despite their high amino acid sequence homology and high overlap in substrate

12 specificity, ThA and ThB isoforms do not drive the same in vivo functions in mice [7]. Of

13 note, only a moderate diminution in glucose plasma level (that did not reach statistical

14 significance) was observed in $S c p 2 / S c p x^{-/-}$mice, when kept under standard laboratory

15 conditions [8]. Whether similar conclusions would have been drawn with $S c p 2^{-/}$mice fed

16 the HFD remains an unresolved issue at present. Regarding the Acox $1^{-/-}$and the $M f p 2^{-/-}$

17 mouse models, it was reported that insulin and glucose levels were normal, both in fed and

18 fasted conditions $[33,59]$. The question arises how the lack of the peroxisomal ThB enzyme

19 leads to hypoglycemia? At present, the underlying molecular mechanisms are far to be

20 understood but it may be hypothesized that the hypoglycemia observed in $T h b^{-/-}$mice is the

21 consequence of the hormonal and metabolic perturbations that include reduced circulating

22 levels of insulin and hepatic glycogen stores. One possibility is that Thb deficiency leads to

23 enhanced hepatic insulin signaling resulting in the suppression of gluconeogenesis and

24 enhanced glycolysis. However, this scenario is rather unlikely because glucose production

25 by the liver (gluconeogenesis) in the fed state is relatively minor and plasma glucose is 
NICOLAS-FRANCES et al., Altered lipid and glucose metabolism in $T h b^{-/}$mice

1 primarily derived from ingestion of nutrients. If we adhere to the notion that glycolysis

2 would be enhanced in $T h b^{-/}$mice, it also implies that glucose oxidation, and in turn the

3 derived pool of pyruvate/acetyl-CoA, are higher providing more substrates for the

4 subsequent enzymatic reactions of the Kreb's cycle. However, the experimental backing of

5 this claim is weak because the mitochondrial succinate dehydrogenase activity and the

6 mitochondrial oxidation rate of palmitoyl-CoA were similar in WT mice and in $T h b^{-/-}$mice

7 (data not shown). Despite this, we cannot rule out that the absence of ThB causes a higher

8 flux of pyruvate towards the Kreb's cycle, explaining at least in part, the hypoglycemia

9 observed in $T h b^{-/}$mice. Intriguingly, compared to WT mice, $T h b^{-/}$mice fed the LFD display

10 similar fat pads mass supporting the notion that ThB may have some functions in glucose

11 metabolism that could be independent of the degree of fat expansion.

12 During the first hours of fasting, hepatic glycogenolysis normally provides most of the 13 circulating blood glucose. Therefore, the steeper drop in blood glucose observed in $T h b^{-/}$

14 mice during early (5h) fasting probably reflects the reduced glycogen reserve and/or an impaired liberation of glucose. After $18 \mathrm{~h}$ and $24 \mathrm{~h}$ of fasting, blood glucose concentrations were similar in WT mice and in $T h b^{-/}$mice reinforcing the notion that gluconeogenesis is likely not responsible for the hypoglycemia observed in fed and short-term fasted $T h b^{-/}$ mice.

$T h b^{-/}$mice display heightened response to exogenous insulin administration when placed on the HFD, which might explain at least in part, their concomitant hypoglycaemia. $T h b^{-/}$mice seems to be more sensitive to insulin than WT mice but the definitive evidence would imply further in vivo experiments that aim at calculating both the percentage stimulation of wholebody glucose utilization and the percentage inhibition of hepatic glucose output by insulin.

24 Future investigations that aim at characterizing the metabolic phenotype of the $T h b^{-/-}$mice under a synthetic diet will also require the determination of the relative contribution of each 
NICOLAS-FRANCES et al., Altered lipid and glucose metabolism in $T h b^{-/}$mice

1 insulin target tissue in the observed hypoglycaemia.

2 Higher glucose utilization due to an impaired mitochondrial FAO in the skeletal muscle

3 could theoretically explain part of the reduction in circulating blood glucose. It was recently

4 reported by Derks and colleagues that inhibition of mitochondrial FAO in vivo slightly

5 suppresses gluconeogenesis but instead enhances clearance of glucose in mice [60]. In our

6 mouse model of global deletion of $T h b$, liver mitochondrial oxidation of palmitate (C16:0)

7 and plasma levels of $\beta$-hydroxybutyrate were similar as compared to WT mice (data not

8 shown). These results suggest that $T h b$ deletion does not massively reverberate on

9 mitochondrial oxidative functions at least in the liver, but whether the same may also apply

10 to the muscle remains to be established. Therefore, increased glucose consumption by the

11 muscle remains a plausible explanation for the hypoglycemia observed in $T h b^{-/}$mice.

12 Similar to previous studies performed by others with mice carrying a single deletion of a

13 peroxisomal enzyme, our data point to the notion that cholesterol metabolism is altered in

$14 \mathrm{Thb}^{-/-}$mice $[11,25,33,45-49]$. However, it was also recently reported that cholesterol

15 synthesis is not altered in peroxisome deficient hepatocytes of liver $P e x 5^{-/}$mice, casting

16 doubts on the real impact of the peroxisome in hepatic cholesterogenesis. Our results

17 strenghten the notion that peroxisome is functionally involved in de novo biosynthesis of

18 cholesterol, as well as in plasma HDL cholesterol metabolism. Interestingly, and in constrast

19 to what we observed for the deletion of $T h b$, the deficiency of peroxisomes as the result of

20 the Pex2 gene knockout was shown to lead to decreased HMG-CoA reductase activity and

21 cholesterol biosynthesis in the kidney [47]. It demonstrates that the cholesterol homeostatic

22 response within a tissue differs according to the identity and function of the peroxisomal

23 gene targeted. At the moment, it is unclear to us why HDL cholesterol was increased in the

24 plasma of $T h b^{-/}$mice. It should be stressed that we found increased Apo-AI protein content

25 in the plasma HDL fraction in $T h b^{-/}$mice, pointing toward an increase in the number of 
NICOLAS-FRANCES et al., Altered lipid and glucose metabolism in $T h b^{-/}$mice

1 HDL particles (unpublished data). In addition to a larger number of circulating HDL

2 particles, it is also possible that $T h b^{-/}$mice display higher content of cholesterol in these

3 HDL particles. From a mechanistic view, it can be expected some changes in hepatic

4 lipoprotein synthesis and/or receptor-mediated lipoprotein cholesterol clearance following

5 the deletion of Thb. However, this aspect remains to be firmly established because Thb

6 deficiency did not change the steady-state mRNA expression level of liver $S r-b I$, a cognate

7 receptor for HDL in the liver, or that of Apo-aI, the major ligand for SR-BI (supplemental

8 Table).

9 Even if we cannot rule out differences in intestinal absorption rates between WT mice and $T h b^{-/}$mice, it is likely that the increase in cholesterol synthesis is the larger factor

11 contributing to elevated plasma total cholesterol levels given the small amount of cholesterol especially in the LFD $(<0,002 \%)$, and in the HFD (to some extent, $\approx 0,015 \%$ ) used in the present study. Supporting this notion, others have previously reported that in mice fed a standard rodent chow containing relatively little cholesterol, the requirement in cholesterol is achieved primarily through de novo biosynthesis [61]. Future studies should be directed at investigating the consequence of $T h b$ deficiency when mice are fed chow alone or supplemented with $2 \%$ cholesterol.

18 Lathosterol content is higher in plasma and kidney in $T h b^{-/-}$mice, a phenotype reminiscent of what is observed in mice deficient for the $S c 5 d$ (lathosterol-5-desaturase) gene [62]. Consistent with this observation, the hypothesis by which SC5D activity (the enzyme that catalyzes the conversion of lathosterol to 7-hydroxycholesterol in the next to last step of cholesterol synthesis) could be reduced in $T h b^{-/}$mice becomes plausible. However, although mice deficient in the $S c 5 d$ gene displayed elevated lathosterol levels compared to WT control mice, a parallel decrease in plasma and liver cholesterol levels is observed, which is not the case for $T h b^{-/}$mice [62]. Therefore, it is unlikely that this postulated mechanism 
NICOLAS-FRANCES et al., Altered lipid and glucose metabolism in $T h b^{-/}$mice

1 could explain the hypercholesterolemia present in $T h b^{-/-}$mice.

2 Importantly, active synthesis of cholesterol by the kidney has been previously noted by

3 others especially under a cholesterol-free diet which is close to the LFD used in the present

4 study, leading to a level accounting for over 50\% of the total renal cholesterol [63].

5 However, because the synthesis by the kidney of the Apo-AI protein is unlikely, it

6 reasonably raises the question to what extent the local increased synthesis of cholesterol is

7 involved in the elevated HDL-cholesterol plasma content observed in $T h b^{-/-}$mice [64].

8 What is also puzzling is that in a previous study using $T h b^{-/-}$mice (on the same genetic

9 background, Sv129) routinely fed the standard commercial pellet diet UAR A03-10

10 (SAFE), we did not find any changes in plasma lathosterol to cholesterol ratio between WT

11 mice and $T h b^{-/}$mice [25]. While the exact reason for this discrepancy remains odd at the

12 moment, the quality of the long-chain fatty acids present in the diet, which is presumably

13 different from the synthetic LFD and HFD used in the present study, together with the

14 cholesterol/oxysterol content that likely differs, may play a prominent role in the observed

15 phenotype.

16 From a biochemical point of view, ThB catalyzes the last step of the $\beta$-oxidation pathway,

17 i.e., the conversion of 3-ketoacyl-CoA into shorter acyl-CoA (by two carbon atoms) together

with acetyl-CoA. Only limited information concerning the substrate specificity of $\mathrm{ThB}$ is available at present. Mature form of ThA and ThB differing only in several amino acids, it came with no surprise that both enzymes equally react with medium and long-straight chain

21 3-oxoacyl-CoAs [7, 65]. However, given the different traits of the phenotype observed in $T h b^{-/-}$mice, it becomes clear that ACCAla (ThA) and ACCAlb (ThB) isoforms are not fully interchangeable. Others have previously reported that acetyl-CoA derived from the peroxisomal $\beta$-oxidation of very long-chain fatty acids and medium-chain dicarboxylic acids would be preferentially channeled to cholesterol synthesis inside the peroxisomes, without 
NICOLAS-FRANCES et al., Altered lipid and glucose metabolism in $T h b^{-/}$mice

1 mixing with the cytosolic acetyl-CoA pool $[11,46,66]$. However, the picture is far from

2 complete because it was also argued that peroxisomal $\beta$-oxidation of (very) long-chain fatty

3 acids supplies acetyl-CoA to the cytosol [67]. Here, we found that the single deletion of Thb

4 was leading to higher C22:0, C24:0 and possibly C26:0 content in the liver of $T h b^{-/}$mice, as

5 a consequence of the probable reduced peroxisomal $\beta$-oxidation pathway. Whatever is the

6 metabolic fate of the peroxisomal pool of acetyl-CoA, the single deletion of $T h b$ may

7 concurrently lead to its lower availability. One would thereby expect reduced de novo

8 cholesterol synthesis in the peroxisome and/or in the cytosol of (kidney) cells in $T h b^{-/-}$mice.

9 However, our results do not support this hypothesis because whole body synthesis of 10 cholesterol was enhanced in $T h b^{-/}$mice fed the LFD or the HFD. Future investigations 11 employing mice with targeted disruption of the Thb gene in the liver or in the kidney should 12 help to precise the respective role of Thb in local cholesterol homeostasis in vivo.

13 Besides conversion of cholesterol into bile salts, the liver also disposes of plasma cholesterol 14 by secretion into bile unmodified. Consistent with the upregulation of the Abcg5/Abcg8 15 canalicular cholesterol transporters in the liver of $T h b^{-/-}$mice, the rate of biliary cholesterol secretion might be increased in response to the accumulation of liver cholesterol. However,

17 proof of this concept will require future investigations that are beyond the scope of the 18 present study.

19 Collectively, our data support the concept that ThB plays a role in hepatic cholesterol and lipoprotein metabolism in mice and opens the road to future investigations regarding bile 21 acid and glucose metabolism.

22 In conclusion, the $T h b^{-/}$mouse model used in this study demonstrates that the peroxisome 23 could play a more important role than solely regulating very-long chain fatty acid $\beta$ 24 oxidation. In particular, our data suggest that regulating the activity of ThB in vivo in mice, 
NICOLAS-FRANCES et al., Altered lipid and glucose metabolism in $T h b^{-/}$mice

1 may provide an additional route for the therapeutic correction of disorders affecting plasma

2 cholesterol and glucose levels.

3

4

5

6

7

8

9

10

Figure 1. Growth restriction and reduced plasma IGF-I and GH levels in Thb $^{-/-}$mice

(a) Body mass and (b) body length of WT mice (white bars, $\mathrm{n}=27$ ) and $T h b^{-/}$mice (gray bars, $n=19$ ) throughout week 4 till week 50 of life. (c) Plasma GH concentration in WT mice $(\mathrm{n}=18)$ and $T h b^{-/}$mice $(\mathrm{n}=16)$ aged of 1 month and half. (d) Plasma IGF-I concentration in WT mice $(\mathrm{n}=16)$ and $T h b^{-/-}$mice $(\mathrm{n}=18)$ aged of 1 month and half. (e) Plasma IGFBP-3 concentration in WT mice $(\mathrm{n}=18)$ and $T h b^{-/-}$mice $(\mathrm{n}=16)$ aged of 1 month and half. (f) Igf- 1 mRNA expression in the liver, brown adipose tissue (BAT), white adipose tissue (WAT) and gastrocnemius of WT mice $(\mathrm{n}=9)$ and $T h b^{-/-}$mice $(\mathrm{n}=11)$ as determined by RT-qPCR. Error bars represent \pm SEM. Differences between WT mice and $T h b^{-/-}$mice were evaluated using the Student's t-test (GraphPad Prism 3 software, San Diego, CA). * p<0.05, ** p<0.01; $* * * \mathrm{p}<0.001$

Figure 2. LFD and HFD feeding of WT mice and $T h b^{-/-}$mice

a) Evolution of body weight during the experimental feeding. Mice were weighed twice a week. Data were expressed as mean $\pm \operatorname{SEM}(n=9$ to $n=12$ per group) b) Area Under the Curve calculated from the evolution in body mass presented in a) c) Graph shows mean body mass of WT mice and $T h b^{-/-}$mice fed the HFD or the LFD for 150-days. d) Body mass changes (expressed in \%) of mice are determined by comparing body mass values at the beginning of the diet intervention and after the LFD or the HFD intervention. The Student's t-test was used to compare the results obtained between two different groups of mice with 
NICOLAS-FRANCES et al., Altered lipid and glucose metabolism in $T h b^{-/}$mice

1 GraphPad Prism 3 software (San Diego, CA). * $\mathrm{p}<0.05$, ** $\mathrm{p}<0.01 ; * * * \mathrm{p}<0.001$, LFD: low-

2 fat diet; HFD: high-fat diet.

3

4 Figure 3. $\boldsymbol{T h b}^{-/-}$mice are protected from HFD-induced adipocyte hypertrophy

5 a) Subcutaneous and b) epididymal and brown adipose tissues weights as a percentage of 6 body weight c) representative light micrographs (magnification 20x) of epididymal fat pads 7 d) adipocytes were counted from eight-to-ten randomly selected fields for each fat 8 epididymal pads (left part); quantification of adipocyte size using software analysis (right 9 part) e) free fatty acids and f) plasma glycerol in the four experimental groups of mice ( $\mathrm{n}=8$ to $\mathrm{n}=11$ per group) that were fasted for $5 \mathrm{~h}$ (starting at $5 \mathrm{am}$ ). Data were expressed as mean \pm SEM. The Student's t-test was used to compare the results obtained between two different groups of mice (GraphPad Prism 3 software, San Diego, CA). * $\mathrm{p}<0.05$, ** $\mathrm{p}<0.01$; *** p<0.001, LFD: low-fat diet; HFD: high-fat diet.

Figure 4. $\mathrm{Thb}^{-/-}$mice display hypoglycemia as the consequence of better insulin sensitivity

a) Insulin sensitivity test was performed in 5-h-fasted WT mice and $T h b^{-/-}$mice previously fed the LFD or the HFD; note that plasma glucose was significantly less in HFD-KO mice compared to HFD-WT mice at time $\mathrm{T}=20 \mathrm{~min}$ and $\mathrm{T}=40 \mathrm{~min} \mathrm{~b}$ ) AUC, area under curves of glucose response expressed as arbitrary units (a.u), c) Plasma glucose in WT and KO mice fed the LFD or the HFD d) plasma glucose in WT and KO mice fed the LFD or the HFD fasted for $0,5,18$, and $24 \mathrm{~h}$; note that plasma glucose level was significantly less in $\mathrm{KO}$ mice compared to WT mice (both LFD and HFD) at time $\mathrm{T}=0$ and $\mathrm{T}=5 \mathrm{~h}$ of fasting e)

24 Endogenous plasma insulin levels in (fed) WT and $T h b^{-/}$mice, f) Glycogen content in muscle of WT mice and $T h b^{-/}$mice, (WT LFD, n= 12; WT HFD, $\mathrm{n}=10$; KO LFD, $\mathrm{n}=8$; KO 
NICOLAS-FRANCES et al., Altered lipid and glucose metabolism in $T h b^{-/}$mice

1 HFD, $n=8$ ). Values are means \pm SEM. The Student's t-test was used to compare the results

2 obtained between two different groups of mice (GraphPad Prism 3 software, San Diego,

$3 \mathrm{CA}) . * \mathrm{p}<0.05, * * \mathrm{p}<0.01 ; * * * \mathrm{p}<0.001$, LFD: low-fat diet; HFD: high-fat diet. $\mathrm{KO}=T h b^{-/-}$.

4

5

6

7 Figure 5. Hepatic glycogen content in WT mice and $T_{h b^{-/}}$mice previously fed the LFD 8 or the HFD.

Hepatic glycogen content was determined as described under "Materials and Methods". a) liver glycogen content in WT mice and $T h b^{-/-}$mice normally fed (ad libitum) the LFD or the HFD. Sacrifice was performed between 10 and $11 \mathrm{am} \mathrm{b)} \mathrm{Relative} \mathrm{liver} \mathrm{glycogen} \mathrm{synthase-2}$ (Gys2) mRNA levels in WT mice and $T h b^{-/-}$mice, as measured by RT-qPCR. Values were expressed as fold-change as compared to WT mice fed LFD arbitrarily set at 1.0. (WT LFD, $\mathrm{n}=10 ;$ WT HFD, $\mathrm{n}=9$; KO LFD, $\mathrm{n}=8$; KO HFD, $\mathrm{n}=9$ ). Values are means \pm SEM. The Student's t-test was used to compare the results obtained between two different groups of mice (GraphPad Prism 3 software, San Diego, CA). * $\mathrm{p}<0.05, * * \mathrm{p}<0.01 ; * * * \mathrm{p}<0.001$, LFD: low-fat diet; HFD: high-fat diet. $\mathrm{KO}=T h b^{-/-}$.

Figure 6. Plasma HDL-cholesterol levels is elevated in $\mathrm{Thb}^{-/-}$mice.

a) Plasma triglyceride and d) plasma cholesterol content was determined in EDTA plasma of WT mice and $T h b^{-/-}$mice fed the LFD or the HFD. b-c) Fast-protein liquid chromatography analysis of plasma triglyceride or e-f) cholesterol of WT mice and $T h b^{-/-}$mice fed the LFD or the HFD. 0,2 $\mathrm{ml}$ of individual mouse plasma sample was passed through a Superose 6-HR column and total triglyceride and cholesterol content of individual fractions was determined 
NICOLAS-FRANCES et al., Altered lipid and glucose metabolism in $T h b^{-/}$mice

1 by an enzymatic method, as described in Materials and Methods. Each point is the mean \pm 2 SEM. (WT LFD, $\mathrm{n}=12 ;$ KO LFD, $\mathrm{n}=8$; WT HFD, $\mathrm{n}=11 ; \mathrm{KO}$ HFD, $\mathrm{n}=10$ ). The

3 corresponding legend for the different circles is indicated in the figure. $\mathrm{KO}=T h b^{-/-}$. LFD:

4 low-fat diet; HFD: high-fat diet.

5

6

7

Figure 7. Whole body cholesterol synthesis as well as hepatic cholesterol efflux and bile acid synthesis are increased in $\boldsymbol{T h b}^{-/-}$mice.

a) Hepatic cholesterol concentration, b) Plasma lathosterol concentration and plasma lathosterol to cholesterol ratio, c) mRNA expression of 3-hydroxy-3-methylglutarylCoenzyme A synthase-1 (Hmg-Coa synthase) and 3-hydroxy-3-methylglutaryl-Coenzyme A reductase (Hmg-Coa reductase), d) mRNA expression of cholesterol-7-alpha hydroxylase (Cyp7a1), cholesterol-17-alpha hydroxylase (CYP17a1) and aldo-keto reductase family 1, member D1 (Akr1d1) in the liver of WT mice and $T h b^{-/-}$mice fed the LFD or the HFD, e) Hepatic content of cholic acid (CA) and deoxycholic acid (DCA), e) mRNA expression of the ATP-binding cassette sub-family G member 5 (Abcg5) and ATP-binding cassette subfamily $\mathrm{G}$ member 8 (Abcg8) in the liver of WT mice and $T h b^{-/-}$mice fed the LFD or the HFD. (WT LFD, $n=12$; WT HFD, $n=12 ; \mathrm{KO}$ LFD, $\mathrm{n}=9$; KO HFD, $\mathrm{n}=8$ ). Values were expressed as fold-change as compared to WT mice fed LFD arbitrarily set at 1.0. The Student's t-test was used to compare the results obtained between two different groups of mice (GraphPad Prism 3 software, San Diego, CA). * $\mathrm{p}<0.05, * * \mathrm{p}<0.01 ; * * * \mathrm{p}<0.001$, LFD: low-fat diet; HFD: high-fat diet. $\mathrm{KO}=T h b^{-/-}$. 
NICOLAS-FRANCES et al., Altered lipid and glucose metabolism in $T h b^{-/}$mice

1 Figure 8. The higher lathosterol to cholesterol ratio is accompanied by the 2 upregulation of cholesterol synthesizing genes in the kidney of $\operatorname{Thb}^{-/-}$mice.

3 a) Kidney lathosterol concentration, b) Kidney lathosterol to cholesterol ratio, c) Kidney 4 cholesterol content, d) mRNA expression of 3-hydroxy-3-methylglutaryl-Coenzyme A 5 synthase-1 (Hmg-Coa synthase), farnesyl di-phosphate synthase (Fdpps) and Sterol 6 Regulatory Element-Binding Protein-2 (Srebp-2) in the kidney, e) Nuclear protein extracts 7 pooled from kidneys of WT mice and $T h b^{-/}$mice fed the LFD or the HFD, were analyzed by 8 Western blotting for the abundance of the mature form of the transcription factor SREBP-2.

9 Histone H1 was used for normalization of nuclear proteins. Quantification of bands relative 10 to histone $\mathrm{H} 1$ is given under the picture corresponding to the blot of SREBP-2, nSREBP-2: nuclear SREBP-2. Ten to twelve mice were used per group. Values were expressed as foldchange as compared to WT mice fed LFD arbitrarily set at 1.0. The Student's t-test was used to compare the results obtained between two different groups of mice (GraphPad Prism 3 software, San Diego, CA). $* \mathrm{p}<0.05, * * \mathrm{p}<0.01 ; * * * \mathrm{p}<0.001$, LFD: low-fat diet; HFD: high-fat diet. $\mathrm{KO}=T h b^{-/}$.

Figure 9: ThB is involved in cholesterol and bile acid metabolism and plays a prominent role in glucose homeostasis in mouse. The important metabolic alterations observed in mice deficient for Thb fed a LFD or a HFD for 5 months are summarized and depicted. ThB: Thiolase B; SREBP2: sterol regulatory element-binding protein-2; Abcg: ATP-binding cassette, subfamily G; Cyp7al: cytochrome P450, family 7, subfamily A, polypeptide 1; Cyp39a1: cytochrome P450, family 39, subfamily A, polypeptide 1; Akrld1: aldo-keto reductase, family 1 , member $\mathrm{d} 1$; CA: cholic acid, DCA: deoxycholic acid; $\uparrow$ : 24 increased; $\downarrow$ : decreased; $\rightarrow:$ unchanged. Note that body weight and growth are also affected by the deletion of $T h b$ in mice fed a normal laboratory chow. 
NICOLAS-FRANCES et al., Altered lipid and glucose metabolism in $T h b^{-/}$mice

2 Table 1: Composition of diets used in the present study.

4 Supplemental Table:

5 Microarray analysis was performed on individual liver mRNA samples $(n=4$ per group)

6 comparing the gene expression signals induced by the deletion of $T h b$ in mice fed the LFD

7 or the HFD. Column C-F: Expression in WT mice fed the LFD was arbitrarily set at 1.0.

8 Changes in gene expression are expressed as fold-changes in comparison with WT mice fed

9 the LFD. LFD: low-fat diet; HFD: high-fat diet.

Supplemental Figure 1:

13 a) Food intake (expressed as g/week/mouse) of the four experimental groups ( $n=9$ to $n=12$ per group) b) Energy intake (expressed as kcal/week/mouse) of the four experimental groups ( $n=9$ to $n=12$ per group) c) Energy intake corrected for body weight (expressed as $\mathrm{kcal} /$ week/g of body weight). The Student's t-test was used to compare the results obtained between two different groups of mice with GraphPad Prism 3 software (San Diego, CA). * $\mathrm{p}<0.05, * * \mathrm{p}<0.01 ; * * * \mathrm{p}<0.001$, LFD: low-fat diet; HFD: high-fat diet.

Supplemental Figure 2:

a) Liver triglyceride content was evaluated using gas-chromatography in WT mice and Thb ${ }^{-/}$ mice at the end of the intervention diet ( $\mathrm{n}=7$ for each condition). b) Liver content of docosanoic acid (C22:0), tetracosanoic acid (C24:0) and hexacosanoic acid (C26:0) in WT

24 mice and $T h b^{-/-}$mice fed the LFD or the HFD, (WT LFD, $\mathrm{n}=11$; WT HFD, $\mathrm{n}=4$; KO LFD, 
NICOLAS-FRANCES et al., Altered lipid and glucose metabolism in $T h b^{-/}$mice

$1 \mathrm{n}=7$; KO HFD, $\mathrm{n}=6$ ). Errors bars represent \pm S.E.M. Significant effects were observed

2 using the Student's t-test. $* \mathrm{p}<0.05, * * \mathrm{p}<0.01$; LFD: low-fat diet; HFD: high-fat diet.

Acknowledgments

5 Supported by grants from the European Union project "Peroxisomes" LSHG-CT-2004-

6 512018, the Regional Council of Burgundy (Conseil Régional de Bourgogne), and the

7 French National Institute for Health and Medical Research (INSERM). We thank members

of the staff from the Centre de Zootechnie (Dijon, France) for their help in mice housing and

breeding. We are also indebted to Pr Myriam Baes (Laboratory of Cell Metabolism,

Department of Pharmaceutical and Pharmacological Sciences, Leuven, Belgium) for access

to the MicroArray Facility in Leuven (MAF, Leuven, Belgium). We also thank members of the MicroArray Facility in Leuven for their excellent technical support and Amandine Bataille (Plateforme d'Imagerie Cellulaire CellImaP, IFR 100 Santé- STIC, Université de Bourgogne, Dijon, France) for her expert technical assistance in histochemistry.

\section{References}

[1] R.J. Wanders, S. Ferdinandusse, P. Brites, S. Kemp, Peroxisomes, lipid metabolism and lipotoxicity, Biochim. Biophys. Acta 1801 (2010) 272-280.

[2] A. Bout, M.M. Franse, J. Collins, L. Blonden, J.M. Tager, R. Benne, Characterization of the gene encoding human peroxisomal 3-oxoacyl-CoA thiolase (ACAA). No large DNA rearrangement in a thiolase-deficient patient, Biochim. Biophys. Acta 1090 (1991) 43-51.

[3] S. Ferdinandusse, E.G. van Grunsven, W. Oostheim, S. Denis, E.M. Hogenhout, I.J. L, C.W. van Roermund, H.R. Waterham, S. Goldfischer, R.J. Wanders, Reinvestigation of peroxisomal 3-ketoacyl-CoA thiolase deficiency: identification of the true defect at the level of d-bifunctional protein, Am. J. Hum. Genet. 70 (2002) 1589-1593.

[4] G. Chevillard, M.C. Clemencet, P. Etienne, P. Martin, T. Pineau, N. Latruffe, V. Nicolas-Frances, Molecular cloning, gene structure and expression profile of two mouse peroxisomal 3-ketoacyl-CoA thiolase genes, BMC Biochem. 5 (2004) 3.

[5] M. Hijikata, J.K. Wen, T. Osumi, T. Hashimoto, Rat peroxisomal 3-ketoacyl-CoA thiolase gene. Occurrence of two closely related but differentially regulated genes, J. Biol. Chem. 265 (1990) 4600-4606.

[6] A.G. Bodnar, R.A. Rachubinski, Cloning and sequence determination of cDNA encoding a second rat liver peroxisomal 3-ketoacyl-CoA thiolase, Gene 91 (1990) 193-199. 
[7] V.D. Antonenkov, P.P. Van Veldhoven, E. Waelkens, G.P. Mannaerts, Comparison of the stability and substrate specificity of purified peroxisomal 3-oxoacyl-CoA thiolases A and B from rat liver, Biochim Biophys Acta 1437 (1999) 136-141.

[8] U. Seedorf, M. Raabe, P. Ellinghaus, F. Kannenberg, M. Fobker, T. Engel, S. Denis, F. Wouters, K.W. Wirtz, R.J. Wanders, N. Maeda, G. Assmann, Defective peroxisomal catabolism of branched fatty acyl coenzyme A in mice lacking the sterol carrier protein2/sterol carrier protein-x gene function, Genes Dev. 12 (1998) 1189-1201.

[9] R.J. Wanders, S. Denis, E. van Berkel, F. Wouters, K.W. Wirtz, U. Seedorf, Identification of the newly discovered $58 \mathrm{kDa}$ peroxisomal thiolase SCPx as the main thiolase involved in both pristanic acid and trihydroxycholestanoic acid oxidation: implications for peroxisomal beta-oxidation disorders, J Inherit Metab Dis 21 (1998) 302305.

[10] B.P. Atshaves, A.L. McIntosh, D. Landrock, H.R. Payne, J.T. Mackie, N. Maeda, J. Ball, F. Schroeder, A.B. Kier, Effect of SCP-x gene ablation on branched-chain fatty acid metabolism, Am. J. Physiol. Gastrointest. Liver Physiol. 292 (2007) G939-951.

[11] I. Weinhofer, M. Kunze, H. Stangl, F.D. Porter, J. Berger, Peroxisomal cholesterol biosynthesis and Smith-Lemli-Opitz syndrome, Biochem Biophys Res Commun 345 (2006) 205-209.

[12] N. Aboushadi, J.E. Shackelford, N. Jessani, A. Gentile, S.K. Krisans, Characterization of peroxisomal 3-hydroxy-3-methylglutaryl coenzyme A reductase in UT2 cells: sterol biosynthesis, phosphorylation, degradation, and statin inhibition, Biochemistry (Mosc). 39 (2000) 237-247.

[13] N. Aboushadi, W.H. Engfelt, V.G. Paton, S.K. Krisans, Role of peroxisomes in isoprenoid biosynthesis, J. Histochem. Cytochem. 47 (1999) 1127-1132.

[14] G. Chevillard, M.C. Clemencet, N. Latruffe, V. Nicolas-Frances, Targeted disruption of the peroxisomal thiolase B gene in mouse: a new model to study disorders related to peroxisomal lipid metabolism, Biochimie 86 (2004) 849-856.

[15] J. Chamouton, F. Hansmannel, J.A. Bonzo, M.C. Clemencet, G. Chevillard, M. Battle, P. Martin, T. Pineau, S. Duncan, F.J. Gonzalez, N. Latruffe, S. Mandard, V. NicolasFrances, The Peroxisomal 3-keto-acyl-CoA thiolase B Gene Expression Is under the Dual Control of PPARalpha and HNF4alpha in the Liver, PPAR Res 2010 (2010) 352957.

[16] S. Mandard, M. Muller, S. Kersten, Peroxisome proliferator-activated receptor alpha target genes, Cell. Mol. Life Sci. 61 (2004) 393-416.

[17] M. Rakhshandehroo, B. Knoch, M. Muller, S. Kersten, Peroxisome proliferatoractivated receptor alpha target genes, PPAR Res 2010.

[18] R. Stienstra, S. Mandard, N.S. Tan, W. Wahli, C. Trautwein, T.A. Richardson, E. Lichtenauer-Kaligis, S. Kersten, M. Muller, The Interleukin-1 receptor antagonist is a direct target gene of PPARalpha in liver, J. Hepatol. 46 (2007) 869-877.

[19] D. Patsouris, S. Mandard, P.J. Voshol, P. Escher, N.S. Tan, L.M. Havekes, W. Koenig, W. Marz, S. Tafuri, W. Wahli, M. Muller, S. Kersten, PPARalpha governs glycerol metabolism, J. Clin. Invest. 114 (2004) 94-103.

[20] S. Mandard, R. Stienstra, P. Escher, N.S. Tan, I. Kim, F.J. Gonzalez, W. Wahli, B. Desvergne, M. Muller, S. Kersten, Glycogen synthase 2 is a novel target gene of peroxisome proliferator-activated receptors, Cell. Mol. Life Sci. 64 (2007) 1145-1157.

[21] P.R. Devchand, H. Keller, J.M. Peters, M. Vazquez, F.J. Gonzalez, W. Wahli, The PPARalpha-leukotriene B4 pathway to inflammation control, Nature 384 (1996) 39-43.

[22] S. Mandard, D. Patsouris, Nuclear control of the inflammatory response in mammals by peroxisome proliferator-activated receptors, PPAR Res 2013 (2013) 613864.

49 [23] M. Bionaz, G.J. Hausman, J.J. Loor, S. Mandard, Physiological and Nutritional

$50 \quad$ Roles of PPAR across Species, PPAR Res 2013 (2013) 807156. 
[24] S. Arnauld, M. Fidaleo, M.C. Clemencet, G. Chevillard, A. Athias, J. Gresti, R.J. Wanders, N. Latruffe, V. Nicolas-Frances, S. Mandard, Modulation of the hepatic fatty acid pool in peroxisomal 3-ketoacyl-CoA thiolase B-null mice exposed to the selective PPARalpha agonist Wy14,643, Biochimie 91 (2009) 1376-1386.

[25] M. Fidaleo, S. Arnauld, M.C. Clemencet, G. Chevillard, M.C. Royer, M. De Bruycker, R.J. Wanders, A. Athias, J. Gresti, P. Clouet, P. Degrace, S. Kersten, M. Espeel, N. Latruffe, V. Nicolas-Frances, S. Mandard, A role for the peroxisomal 3-ketoacyl-CoA thiolase B enzyme in the control of PPARalpha-mediated upregulation of SREBP-2 target genes in the liver, Biochimie 93 (2011) 876-891.

[26] D. Patsouris, J.K. Reddy, M. Muller, S. Kersten, Peroxisome Proliferator-Activated Receptor \{alpha\} Mediates the Effects of High-Fat Diet on Hepatic Gene Expression, Endocrinology 147 (2006) 1508-1516.

[27] D. Hall, C. Poussin, V.R. Velagapudi, C. Empsen, M. Joffraud, J.S. Beckmann, A.E. Geerts, Y. Ravussin, M. Ibberson, M. Oresic, B. Thorens, Peroxisomal and microsomal lipid pathways associated with resistance to hepatic steatosis and reduced pro-inflammatory state, J Biol Chem 285 (2010) 31011-31023.

[28] S. Kozawa, A. Honda, N. Kajiwara, Y. Takemoto, T. Nagase, H. Nikami, Y. Okano, S. Nakashima, N. Shimozawa, Induction of peroxisomal lipid metabolism in mice fed a high-fat diet, Molecular medicine reports 4 (2011) 1157-1162.

[29] R. Stienstra, S. Mandard, D. Patsouris, C. Maass, S. Kersten, M. Muller, Peroxisome Proliferator-Activated Receptor \{alpha\} Protects against Obesity-Induced Hepatic Inflammation, Endocrinology 148 (2007) 2753-2763.

[30] A.L. Sberna, M. Assem, T. Gautier, J. Grober, B. Guiu, A. Jeannin, J.P. Pais de Barros, A. Athias, L. Lagrost, D. Masson, Constitutive androstane receptor activation stimulates faecal bile acid excretion and reverse cholesterol transport in mice, J Hepatol 55 (2011) 154-161.

[31] J.V. Passonneau, V.R. Lauderdale, A comparison of three methods of glycogen measurement in tissues, Anal Biochem 60 (1974) 405-412.

[32] G. Denis, S. Mandard, C. Humblet, M. Verlaet, J. Boniver, D. Stehelin, M.P. Defresne, D. Regnier, Nuclear localization of a new c-cbl related protein, CARP 90, during in vivo thymic apoptosis in mice, Cell. Death Differ. 6 (1999) 689-697.

[33] K. Martens, E. Ver Loren van Themaat, M.F. van Batenburg, M. Heinaniemi, S. Huyghe, P. Van Hummelen, C. Carlberg, P.P. Van Veldhoven, A. Van Kampen, M. Baes, Coordinate induction of PPARalpha and SREBP2 in multifunctional protein 2 deficient mice, Biochim. Biophys. Acta (2008).

[34] S. Yakar, J.L. Liu, B. Stannard, A. Butler, D. Accili, B. Sauer, D. LeRoith, Normal growth and development in the absence of hepatic insulin-like growth factor I, Proc. Natl. Acad. Sci. U S A 96 (1999) 7324-7329.

[35] S. Yakar, J.L. Liu, A.M. Fernandez, Y. Wu, A.V. Schally, J. Frystyk, S.D. Chernausek, W. Mejia, D. Le Roith, Liver-specific igf-1 gene deletion leads to muscle insulin insensitivity, Diabetes 50 (2001) 1110-1118.

[36] R.K. Stoving, A. Flyvbjerg, J. Frystyk, S. Fisker, J. Hangaard, M. Hansen-Nord, C. Hagen, Low serum levels of free and total insulin-like growth factor I (IGF-I) in patients with anorexia nervosa are not associated with increased IGF-binding protein-3 proteolysis, J. Clin. Endocrinol. Metab. 84 (1999) 1346-1350.

[37] B. Ahren, E. Simonsson, A.J. Scheurink, H. Mulder, U. Myrsen, F. Sundler, Dissociated insulinotropic sensitivity to glucose and carbachol in high-fat diet-induced insulin resistance in C57BL/6J mice, Metabolism. 46 (1997) 97-106.

[38] S. Mandard, F. Zandbergen, E. van Straten, W. Wahli, F. Kuipers, M. Muller, S. Kersten, The fasting-induced adipose factor/angiopoietin-like protein 4 is physically 
associated with lipoproteins and governs plasma lipid levels and adiposity, J Biol Chem 281 (2006) 934-944.

[39] R. Stienstra, J.A. van Diepen, C.J. Tack, M.H. Zaki, F.L. van de Veerdonk, D. Perera, G.A. Neale, G.J. Hooiveld, A. Hijmans, I. Vroegrijk, S. van den Berg, J. Romijn, P.C. Rensen, L.A. Joosten, M.G. Netea, T.D. Kanneganti, Inflammasome is a central player in the induction of obesity and insulin resistance, Proc Natl Acad Sci U S A 108 (2011) 15324-15329.

[40] C. Duval, U. Thissen, S. Keshtkar, B. Accart, R. Stienstra, M.V. Boekschoten, T. Roskams, S. Kersten, M. Muller, Adipose tissue dysfunction signals progression of hepatic steatosis towards nonalcoholic steatohepatitis in C57BL/6 mice, Diabetes 59 (2010) 31813191.

[41] B.B. Kahn, J.S. Flier, Obesity and insulin resistance, J Clin Invest 106 (2000) 473481.

[42] B. Meissburger, J. Ukropec, E. Roeder, N. Beaton, M. Geiger, D. Teupser, B. Civan, W. Langhans, P.P. Nawroth, D. Gasperikova, G. Rudofsky, C. Wolfrum, Adipogenesis and insulin sensitivity in obesity are regulated by retinoid-related orphan receptor gamma, EMBO molecular medicine 3 (2011) 637-651.

[43] M. Jernas, J. Palming, K. Sjoholm, E. Jennische, P.A. Svensson, B.G. Gabrielsson, M. Levin, A. Sjogren, M. Rudemo, T.C. Lystig, B. Carlsson, L.M. Carlsson, M. Lonn, Separation of human adipocytes by size: hypertrophic fat cells display distinct gene expression, Faseb. J. 20 (2006) 1540-1542.

[44] V.S. Nunes, C.C. Leanca, N.B. Panzoldo, E. Parra, P.M. Cazita, E.R. Nakandakare, E.C. de Faria, E.C. Quintao, HDL-C concentration is related to markers of absorption and of cholesterol synthesis: Study in subjects with low vs. high HDL-C, Clin. Chim. Acta 412 (2011) 176-180.

[45] W.J. Kovacs, K.N. Charles, K.M. Walter, J.E. Shackelford, T.M. Wikander, M.J. Richards, S.J. Fliesler, S.K. Krisans, P.L. Faust, Peroxisome deficiency-induced ER stress and SREBP-2 pathway activation in the liver of newborn PEX2 knock-out mice, Biochim Biophys Acta 1821 (2012) 895-907.

[46] W.J. Kovacs, K.N. Tape, J.E. Shackelford, X. Duan, T. Kasumov, J.K. Kelleher, H. Brunengraber, S.K. Krisans, Localization of the pre-squalene segment of the isoprenoid biosynthetic pathway in mammalian peroxisomes, Histochem. Cell Biol. 127 (2007) 273290.

[47] W.J. Kovacs, J.E. Shackelford, K.N. Tape, M.J. Richards, P.L. Faust, S.J. Fliesler, S.K. Krisans, Disturbed cholesterol homeostasis in a peroxisome-deficient PEX2 knockout mouse model, Mol. Cell. Biol. 24 (2004) 1-13.

[48] W.J. Kovacs, L.M. Olivier, S.K. Krisans, Central role of peroxisomes in isoprenoid biosynthesis, Prog. Lipid Res. 41 (2002) 369-391.

[49] A. Mazein, S. Watterson, W.Y. Hsieh, W.J. Griffiths, P. Ghazal, A comprehensive machine-readable view of the mammalian cholesterol biosynthesis pathway, Biochem Pharmacol 86 (2013) 56-66.

[50] H.J. Kempen, J.F. Glatz, J.A. Gevers Leuven, H.A. van der Voort, M.B. Katan, Serum lathosterol concentration is an indicator of whole-body cholesterol synthesis in humans, J. Lipid. Res. 29 (1988) 1149-1155.

[51] L. Lichtenstein, J.F. Berbee, S.J. van Dijk, K.W. van Dijk, A. Bensadoun, I.P. Kema, P.J. Voshol, M. Muller, P.C. Rensen, S. Kersten, Angptl4 upregulates cholesterol synthesis in liver via inhibition of LPL- and HL-dependent hepatic cholesterol uptake, Arterioscler. Thromb. Vasc. Biol. 27 (2007) 2420-2427. 
[52] M. Hashimoto, K. Kobayashi, M. Watanabe, Y. Kazuki, S. Takehara, A. Inaba, S.I. Nitta, N. Senda, M. Oshimura, K. Chiba, Knockout of mouse Cyp3a gene enhances synthesis of cholesterol and bile acid in the liver, J Lipid Res (2013).

[53] B. Lindenthal, T.A. Aldaghlas, A.L. Holleran, T. Sudhop, H.K. Berthold, K. Von Bergmann, J.K. Kelleher, Isotopomer spectral analysis of intermediates of cholesterol synthesis in human subjects and hepatic cells, Am J Physiol Endocrinol Metab 282 (2002) E1222-1230.

8 [54] A.L. Wu, H.G. Windmueller, Relative contributions by liver and intestine to individual plasma apolipoproteins in the rat, J Biol Chem 254 (1979) 7316-7322.

[55] J. Mi, E. Kirchner, S. Cristobal, Quantitative proteomic comparison of mouse peroxisomes from liver and kidney, Proteomics 7 (2007) 1916-1928.

[56] S. Yakar, C.J. Rosen, W.G. Beamer, C.L. Ackert-Bicknell, Y. Wu, J.L. Liu, G.T. Ooi, J. Setser, J. Frystyk, Y.R. Boisclair, D. LeRoith, Circulating levels of IGF-1 directly regulate bone growth and density, J Clin Invest 110 (2002) 771-781.

[57] C.Y. Fan, J. Pan, N. Usuda, A.V. Yeldandi, M.S. Rao, J.K. Reddy, Steatohepatitis, spontaneous peroxisome proliferation and liver tumors in mice lacking peroxisomal fatty acyl-CoA oxidase. Implications for peroxisome proliferator-activated receptor alpha natural ligand metabolism, J. Biol. Chem. 273 (1998) 15639-15645.

[58] M. Baes, S. Huyghe, P. Carmeliet, P.E. Declercq, D. Collen, G.P. Mannaerts, P.P. Van Veldhoven, Inactivation of the peroxisomal multifunctional protein-2 in mice impedes the degradation of not only 2-methyl-branched fatty acids and bile acid intermediates but also of very long chain fatty acids, J. Biol. Chem. 275 (2000) 16329-16336.

[59] T. Hashimoto, W.S. Cook, C. Qi, A.V. Yeldandi, J.K. Reddy, M.S. Rao, Defect in peroxisome proliferator-activated receptor alpha-inducible fatty acid oxidation determines the severity of hepatic steatosis in response to fasting, J Biol Chem 275 (2000) 2891828928.

[60] T.G. Derks, T.H. van Dijk, A. Grefhorst, J.P. Rake, G.P. Smit, F. Kuipers, D.J. Reijngoud, Inhibition of mitochondrial fatty acid oxidation in vivo only slightly suppresses gluconeogenesis but enhances clearance of glucose in mice, Hepatology 47 (2008) 10321042.

[61] Y. Osono, L.A. Woollett, J. Herz, J.M. Dietschy, Role of the low density lipoprotein receptor in the flux of cholesterol through the plasma and across the tissues of the mouse, $\mathrm{J}$ Clin Invest 95 (1995) 1124-1132.

[62] P.A. Krakowiak, C.A. Wassif, L. Kratz, D. Cozma, M. Kovarova, G. Harris, A. Grinberg, Y. Yang, A.G. Hunter, M. Tsokos, R.I. Kelley, F.D. Porter, Lathosterolosis: an inborn error of human and murine cholesterol synthesis due to lathosterol 5-desaturase deficiency, Hum. Mol. Genet. 12 (2003) 1631-1641.

[63] H.A. Jurevics, P. Morell, Sources of cholesterol for kidney and nerve during development, J Lipid Res 35 (1994) 112-120.

[64] M.L. Blue, D.L. Williams, S. Zucker, S.A. Khan, C.B. Blum, Apolipoprotein E synthesis in human kidney, adrenal gland, and liver, Proc Natl Acad Sci U S A 80 (1983) 283-287.

[65] V.D. Antonenkov, P.P. Van Veldhoven, E. Waelkens, G.P. Mannaerts, Substrate specificities of 3-oxoacyl-CoA thiolase A and sterol carrier protein 2/3-oxoacyl-CoA thiolase purified from normal rat liver peroxisomes. Sterol carrier protein $2 / 3$-oxoacyl-CoA thiolase is involved in the metabolism of 2-methyl-branched fatty acids and bile acid intermediates, J Biol Chem 272 (1997) 26023-26031.

[66] F. Bian, T. Kasumov, K.R. Thomas, K.A. Jobbins, F. David, P.E. Minkler, C.L. Hoppel, H. Brunengraber, Peroxisomal and mitochondrial oxidation of fatty acids in the 
NICOLAS-FRANCES et al., Altered lipid and glucose metabolism in $T h b^{-/}$mice

heart, assessed from the 13C labeling of malonyl-CoA and the acetyl moiety of citrate, $\mathrm{J}$ Biol Chem 280 (2005) 9265-9271.

[67] A.E. Reszko, T. Kasumov, F. David, K.A. Jobbins, K.R. Thomas, C.L. Hoppel, H. Brunengraber, C. Des Rosiers, Peroxisomal fatty acid oxidation is a substantial source of the acetyl moiety of malonyl-CoA in rat heart, J Biol Chem 279 (2004) 19574-19579.

6

7

8

9

10

11

12

13

14

15

16

17

18

19

20

21

22

23 
a

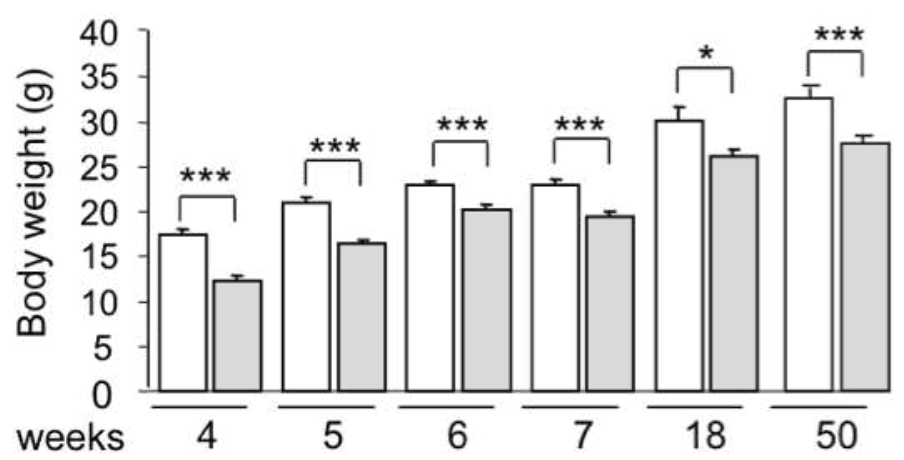

C

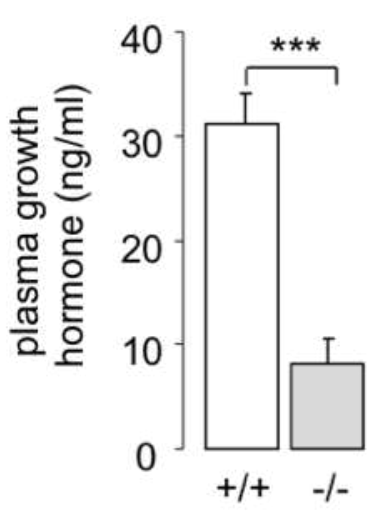

d

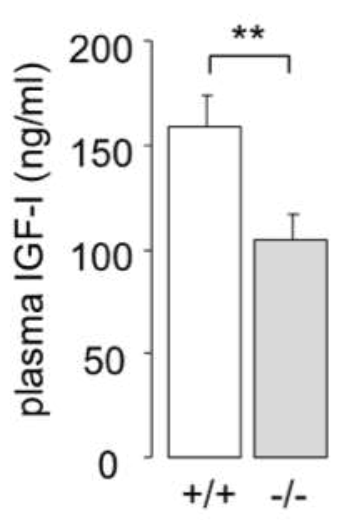

b

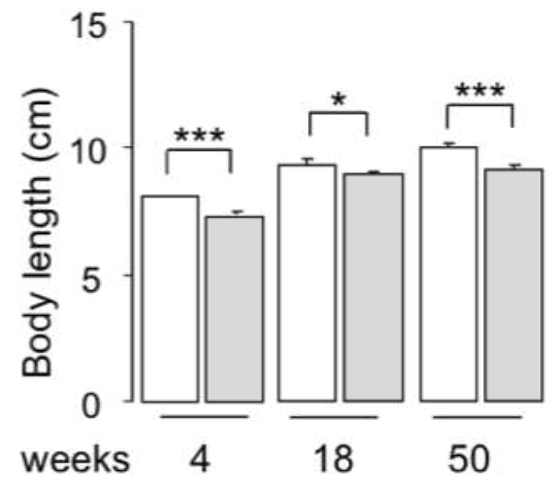

e

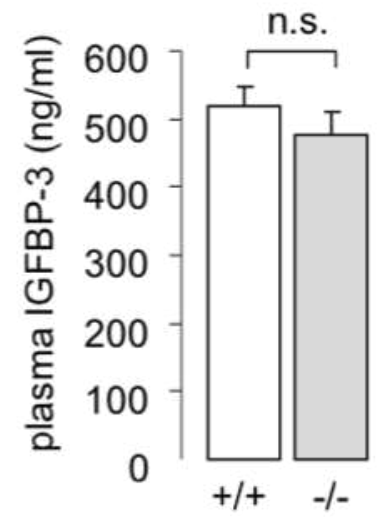

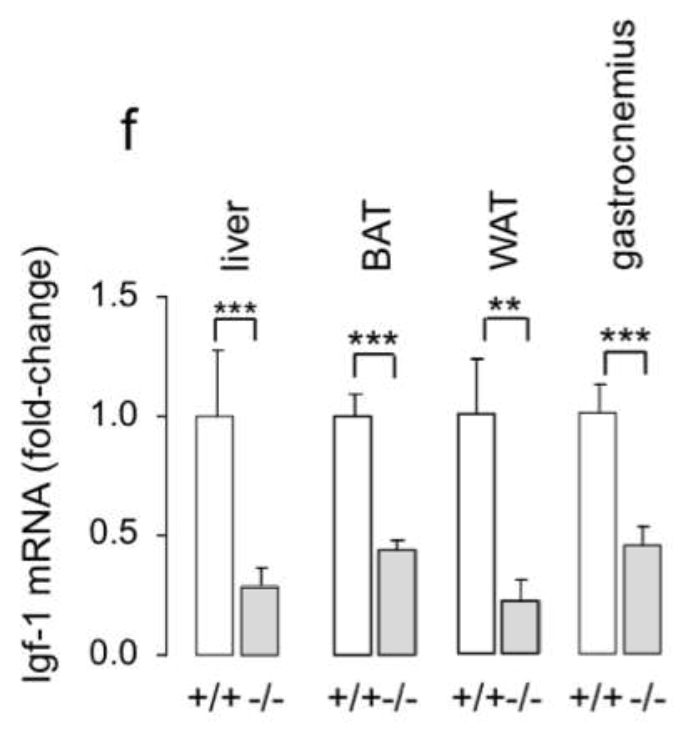

NICOLAS-FRANCES et al., Fig. 1 
a

9

10

11
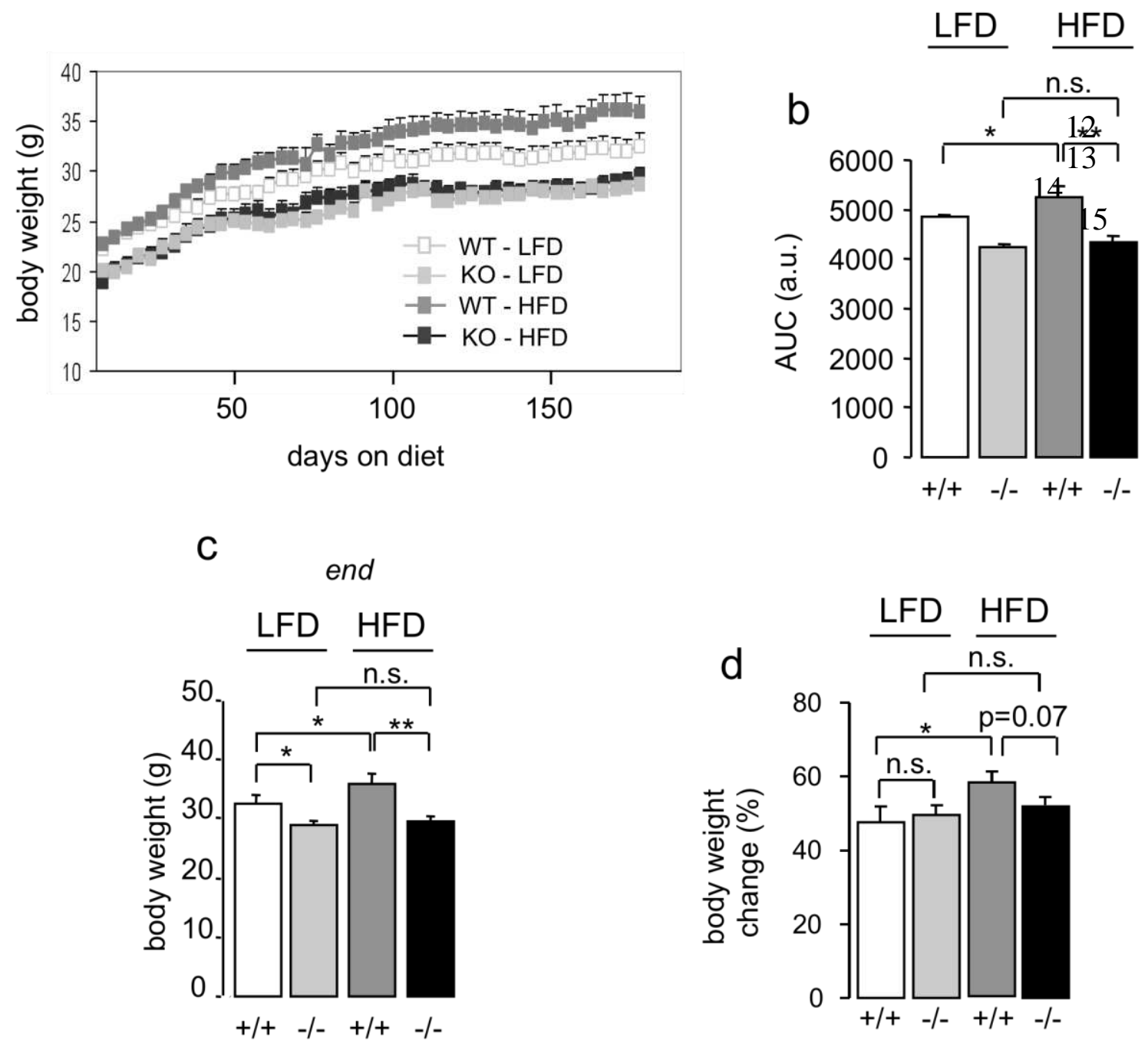

NICOLAS-FRANCES et al., Fig. 2 

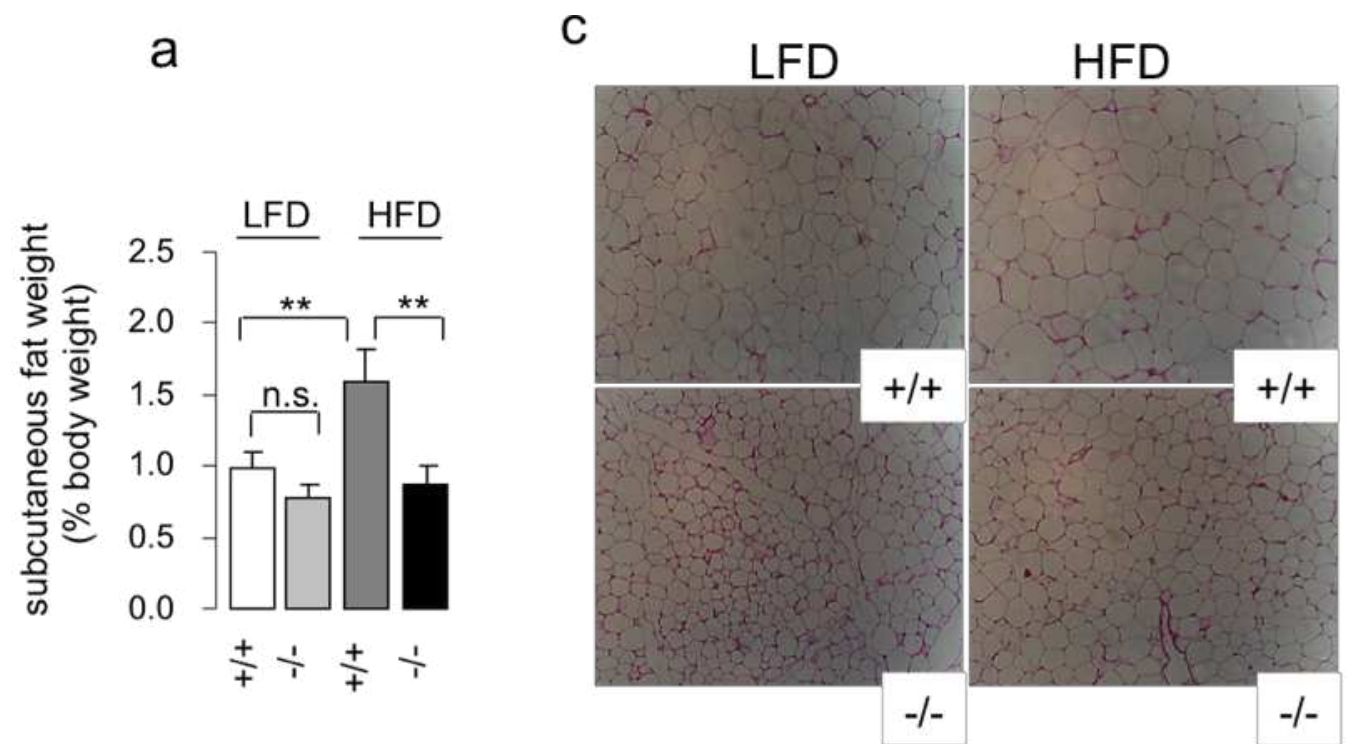

b
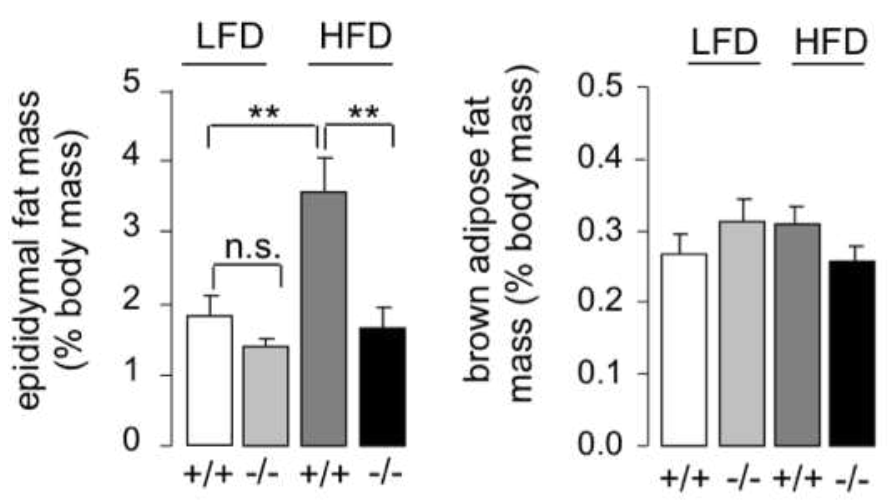

e
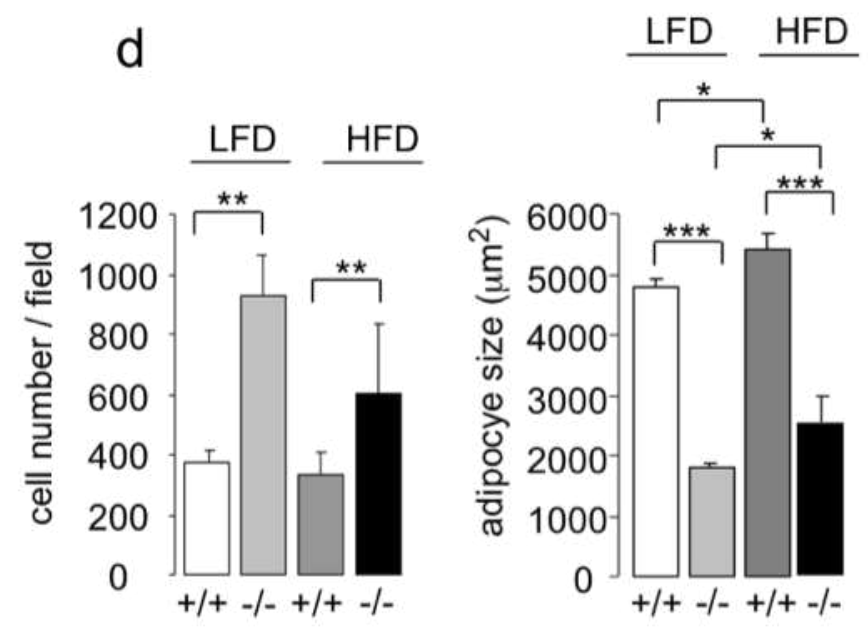
a

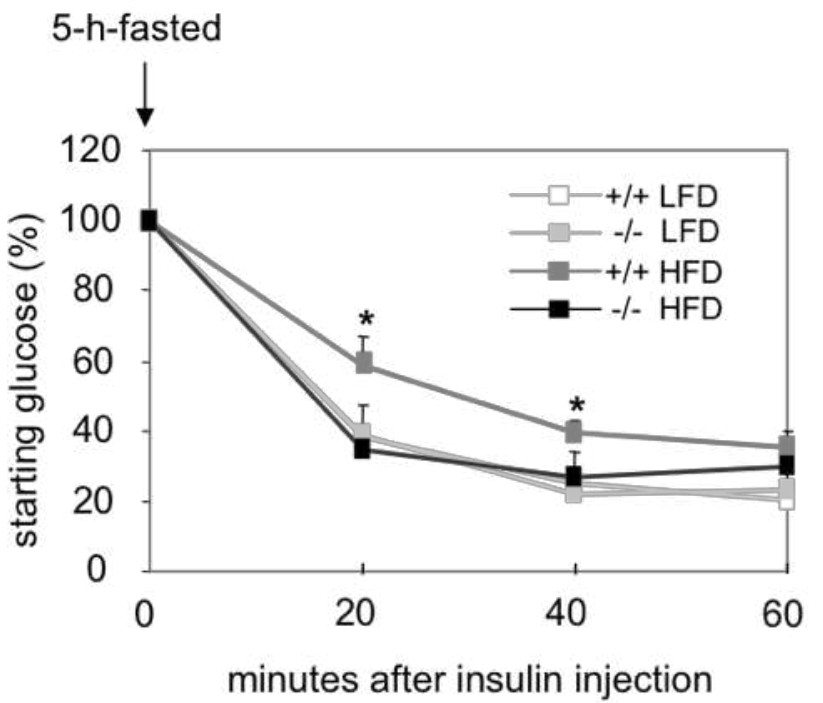

b

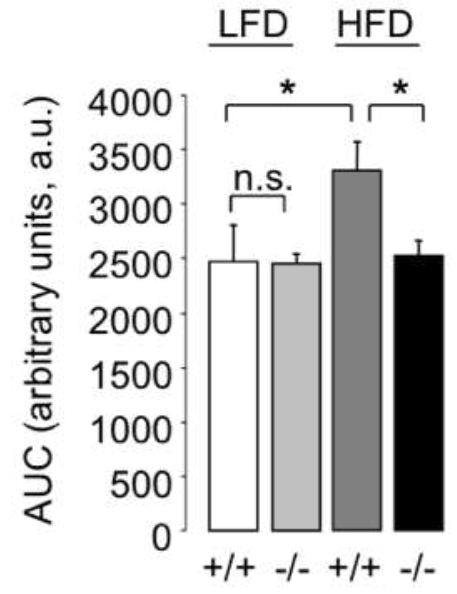

C
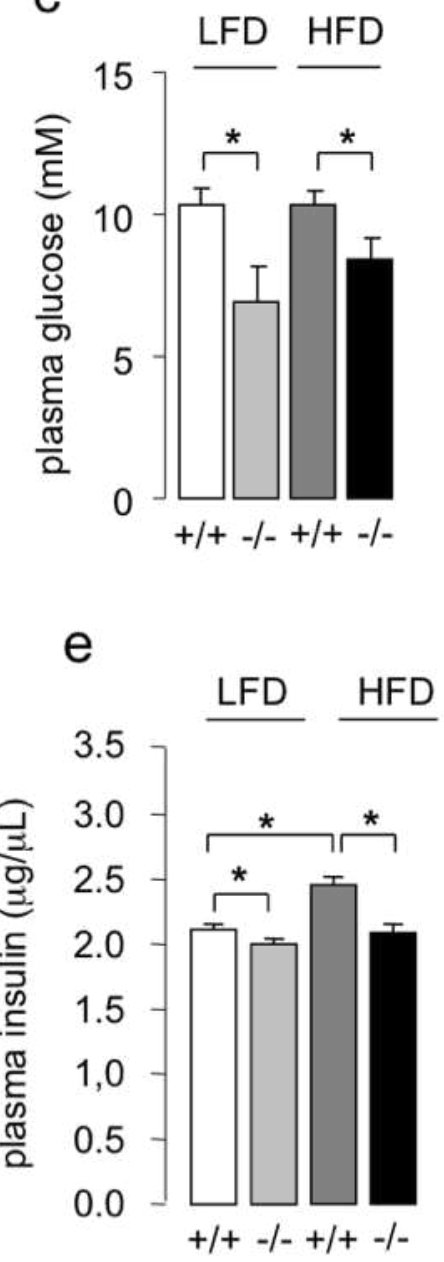

d
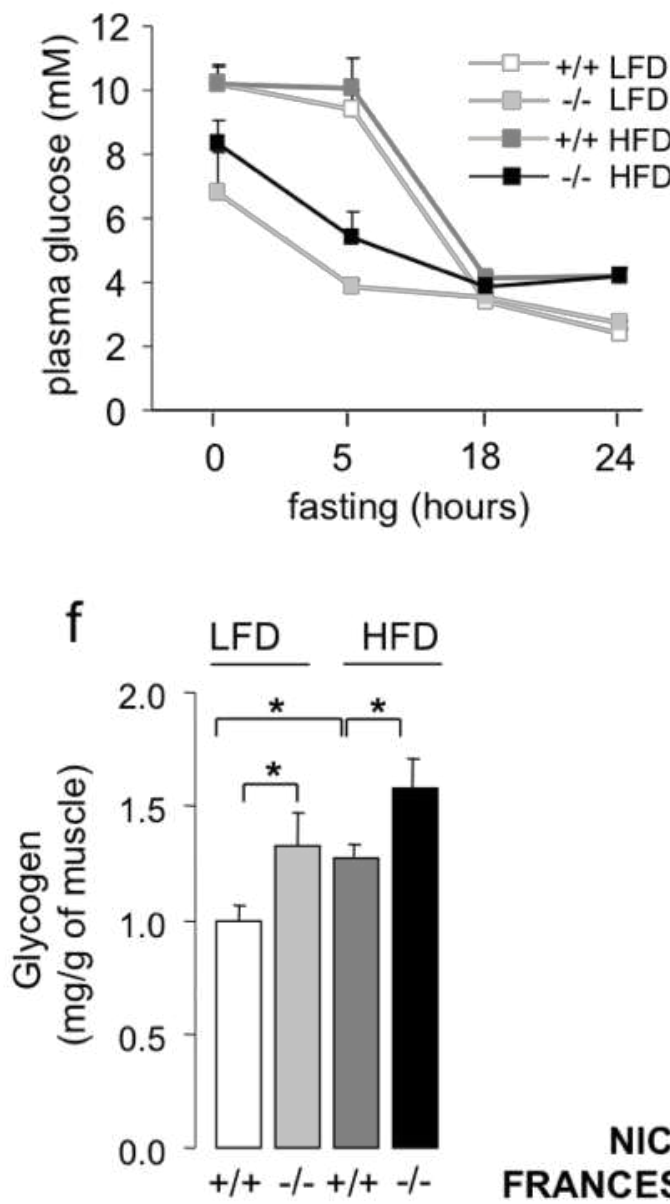

NICOLAS-

FRANCES et al., Fig. 4 
b

a
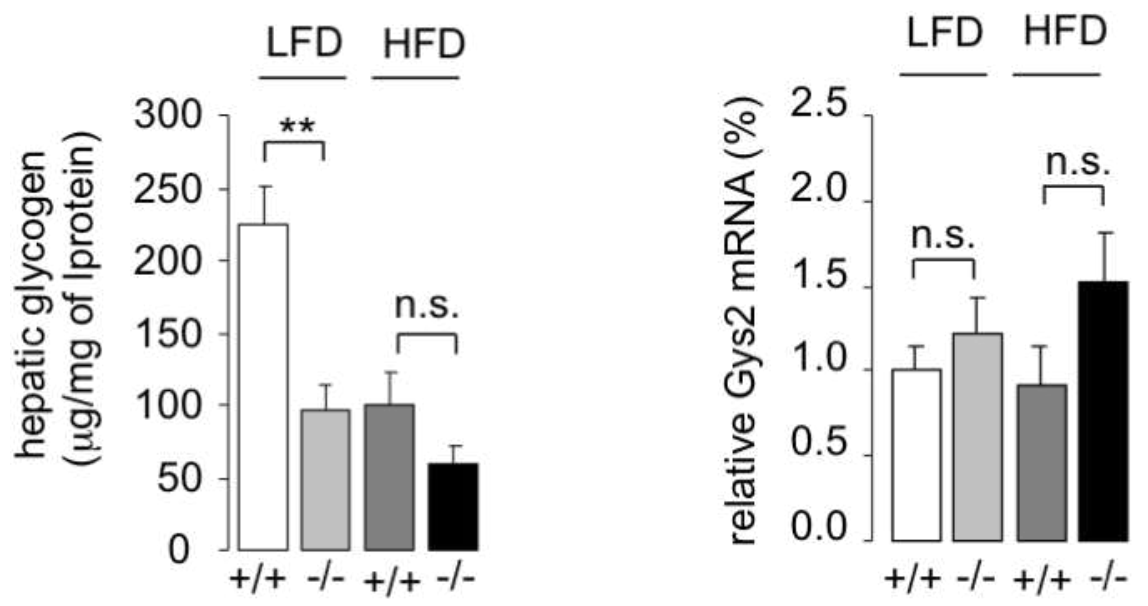

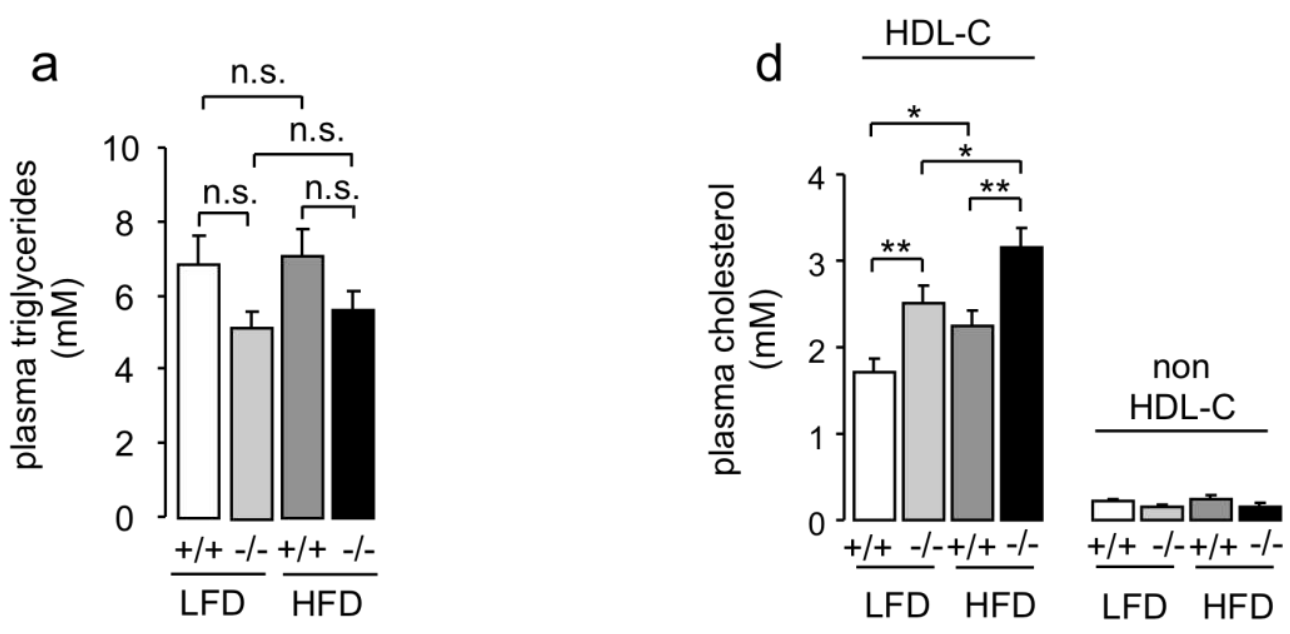

b

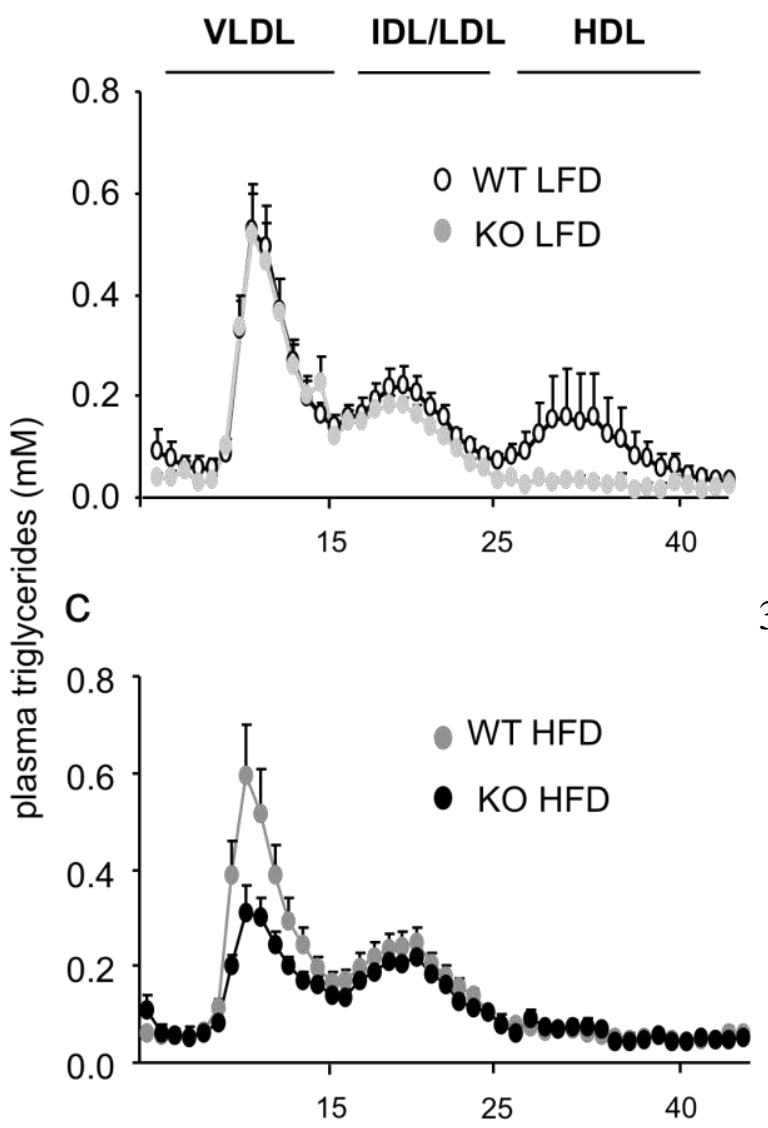

Fraction number

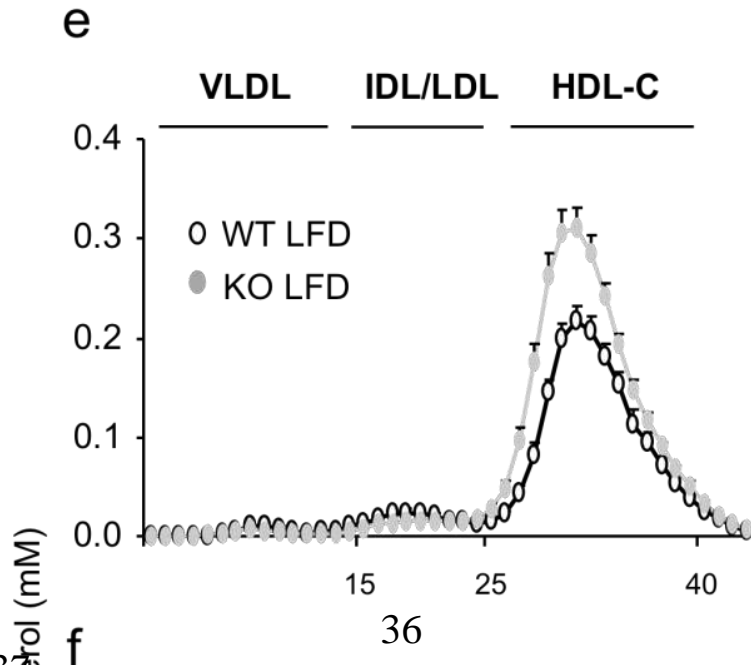

$3 \frac{1}{0}$
$\frac{1}{0}$
$\frac{1}{0}$
$\frac{1}{0}$
$\frac{\pi}{0}$
$\frac{1}{0}$
$\frac{\pi}{2}$

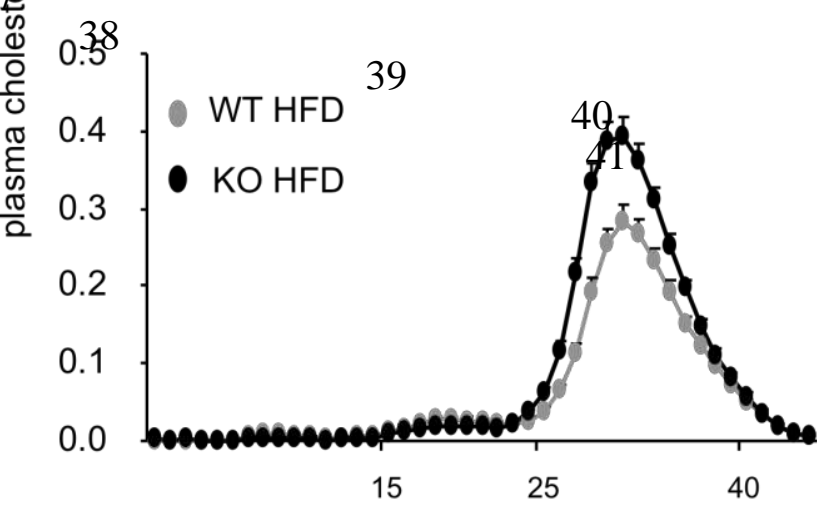

Fraction number

NICOLAS-FRANCES et al., Fig. 6 


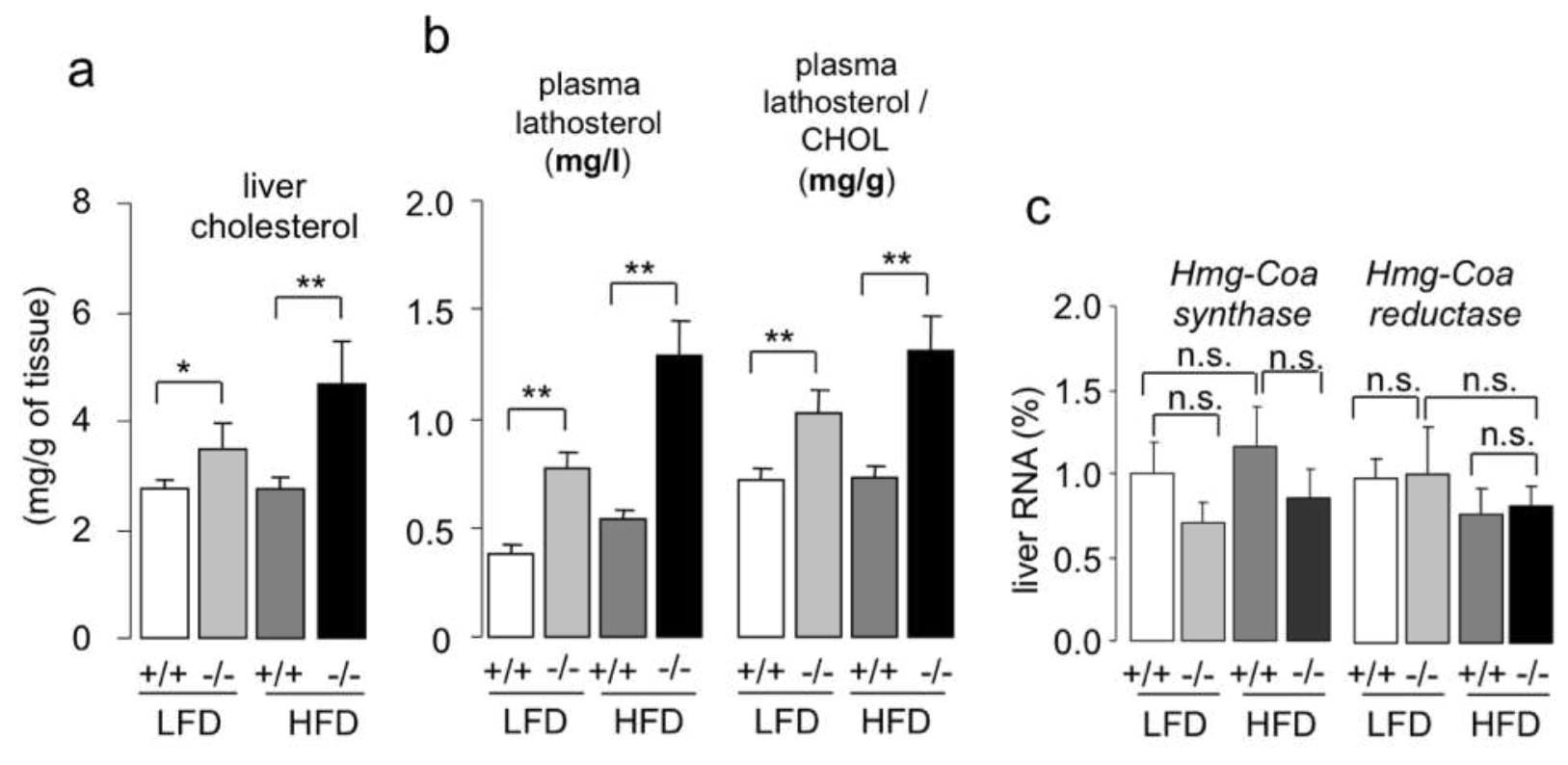

d

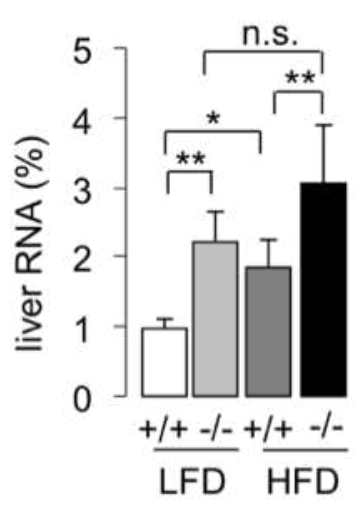

Сур39a1

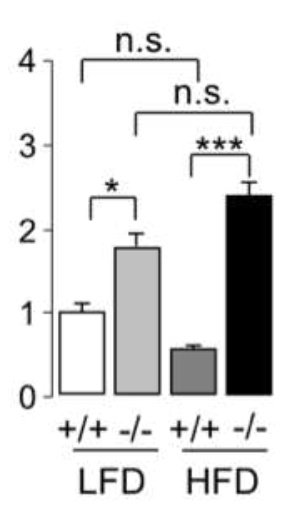

Akr1d1

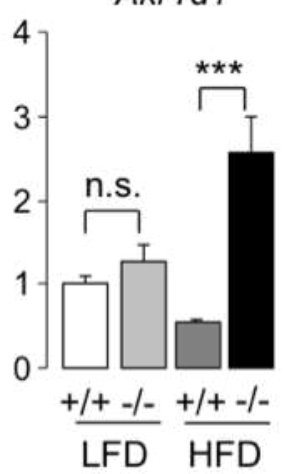

e

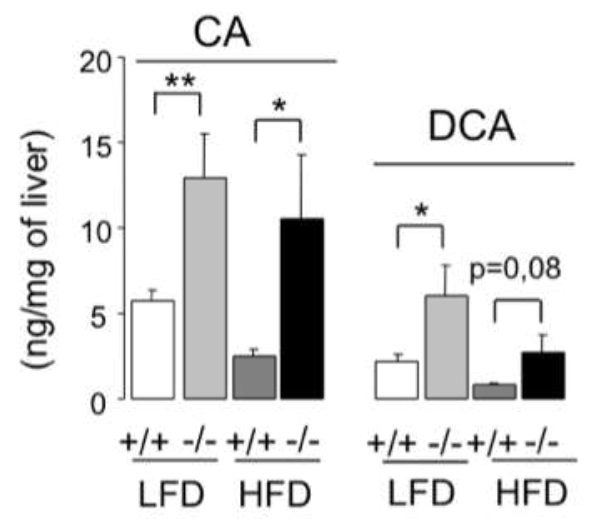

f

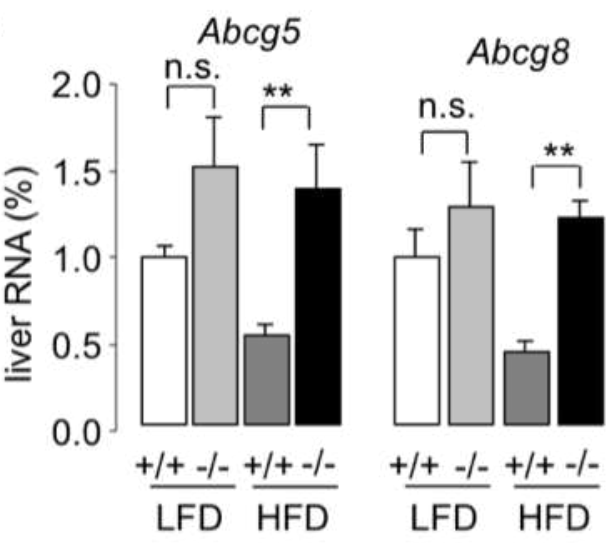

NICOLAS-FRANCES et al., Fig.7 
a

kidney

lathosterol

20. $(\mu \mathrm{g} / \mathrm{g}$ of tissue)

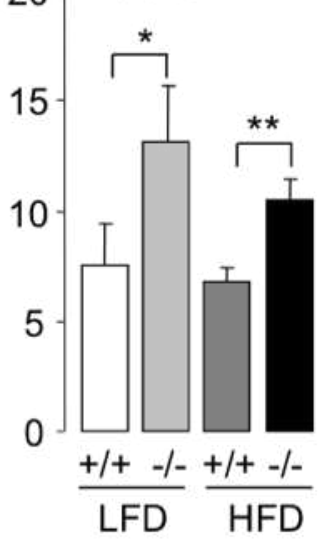

d

Hmg-Coa

synthase

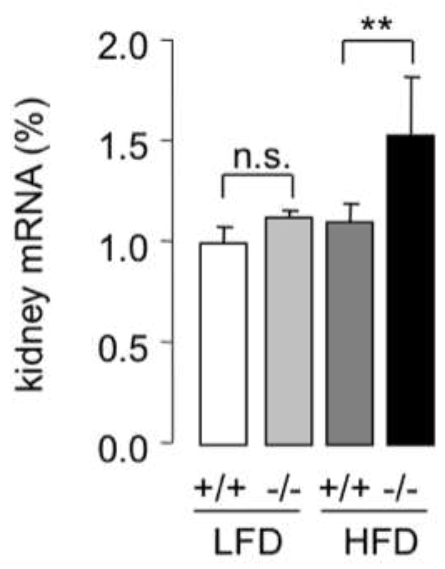

b

kidney

lathosterol /

$\mathrm{CHOL}$

$(\mu \mathrm{g} / \mathrm{mg})$

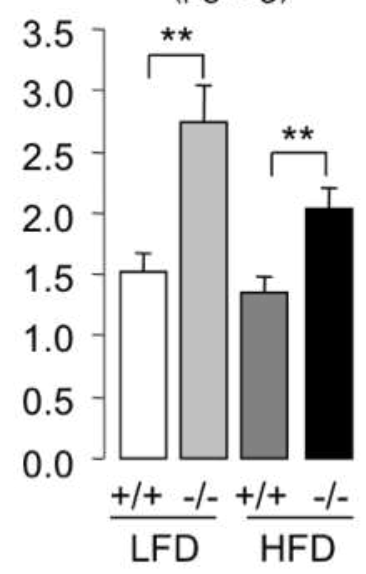

Fdpps

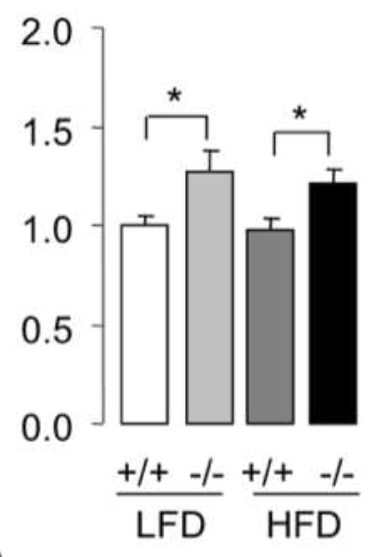

e

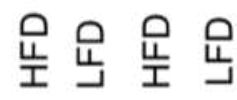

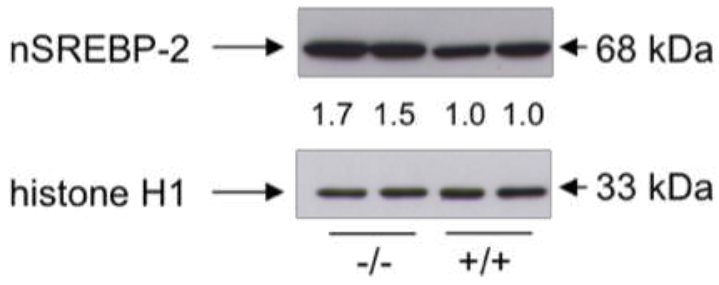

C

kidney

cholesterol

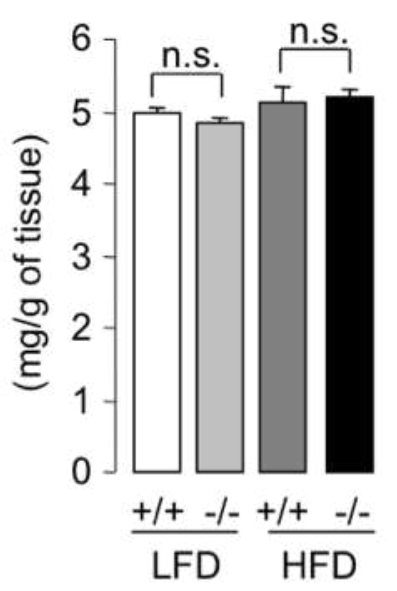

Srebp-2

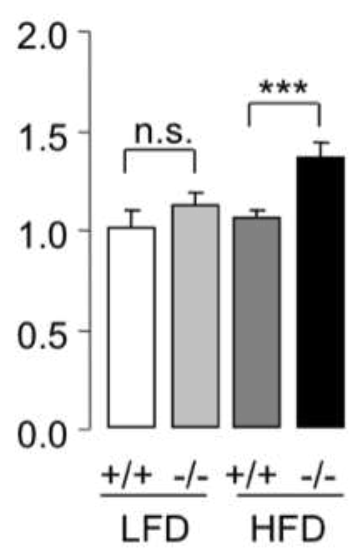




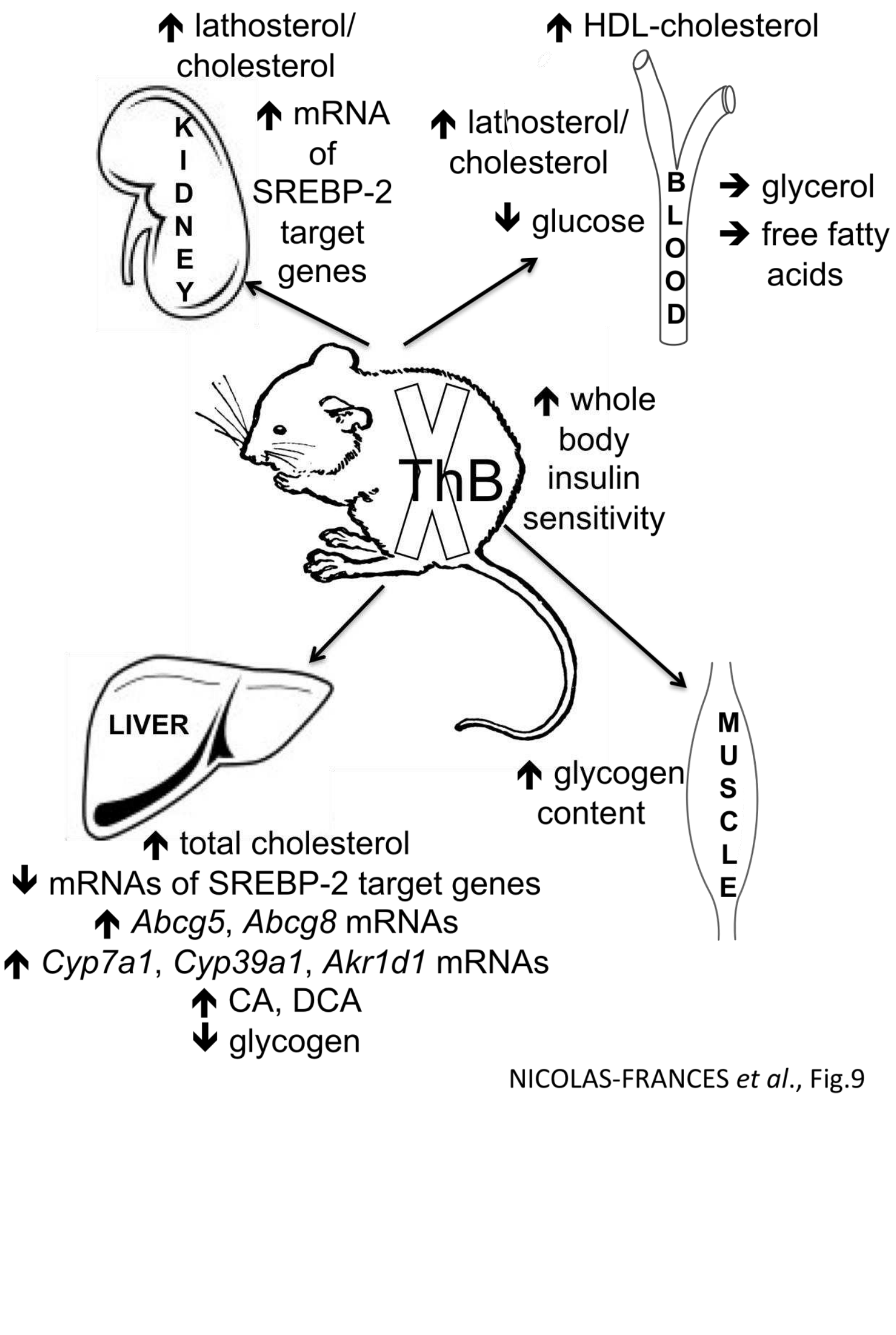




\begin{tabular}{lcc} 
& $\begin{array}{c}\text { D12450B } \\
(\text { LFD })\end{array}$ & $\begin{array}{c}\text { D12451 } \\
(\text { HFD })\end{array}$ \\
\hline Protein $(\mathrm{g} / 100 \mathrm{~g})$ & 19.2 & 24.0 \\
Carbohydrate $(\mathrm{g} / \mathrm{100g})$ & 67.3 & 41.0 \\
$\quad$ Starch & 29.9 & 8.5 \\
$\quad$ Sucrose & 33.2 & 20.1 \\
Fat $(\mathrm{g} / 100 \mathrm{~g})$ & 4.3 & 24.0
\end{tabular}

ingredient $(\mathbf{g})$

Lard

20.0

177.5

C14, Myristic

0.2

1.6

C14:1, Myristoleic

0.1

0.9

C16, Palmitic

7.2

43.2

C16:1, Palmitoleic

0.8

6.7

C18, Stearic

3.6

24.6

C18:1, Oleic

14.3

79.0

C18:2, Linoleic

15.1

28.6

C18:3, Linolenic

2.2

3.7

C20:4, Arachidonic

0.3

3.0

Total (g)

saturated

monounsaturated

11.0

15.2

69.4

polyunsaturated

17.6

86.7

35.4

Total (\%)

saturated

monounsaturated

25.1

36.3

$34.7 \quad 45.3$

polyunsaturated

42.0

18.5

Cholesterol (\%; w/w)

$0.00136 \quad 0.01489$

Cholesterol $(\mathrm{mg} / \mathrm{kg})$

13.6

148.9

NICOLAS-FRANCES et al., Table 1 
NICOLAS-FRANCES et al., Altered lipid and glucose metabolism in $T h b^{-/}$mice

a

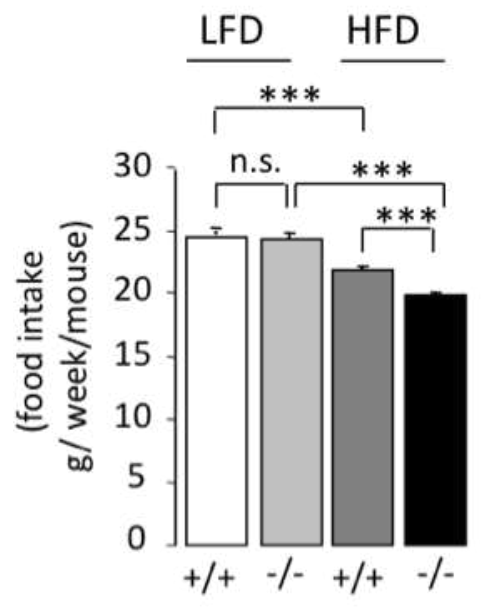

b

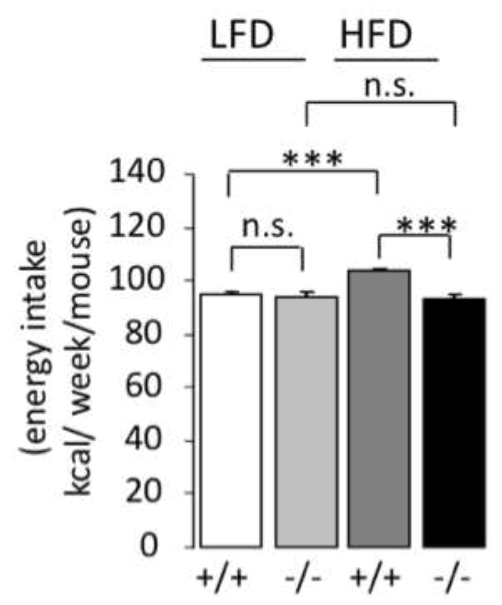

C

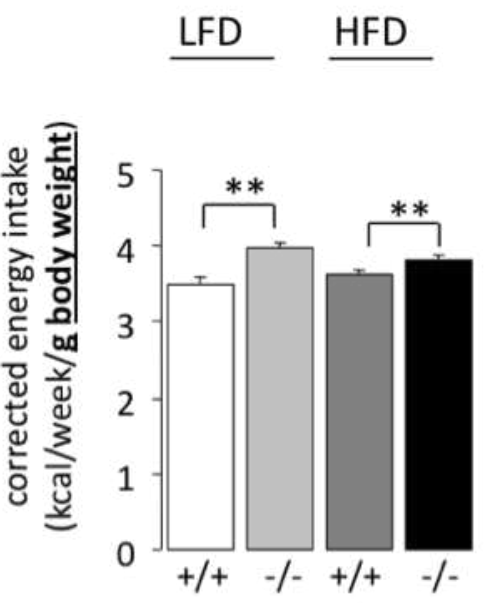


a

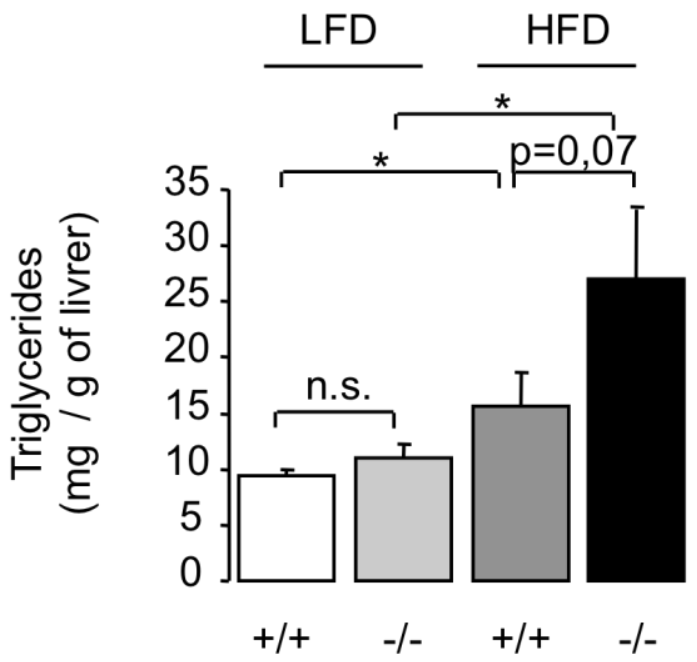

b
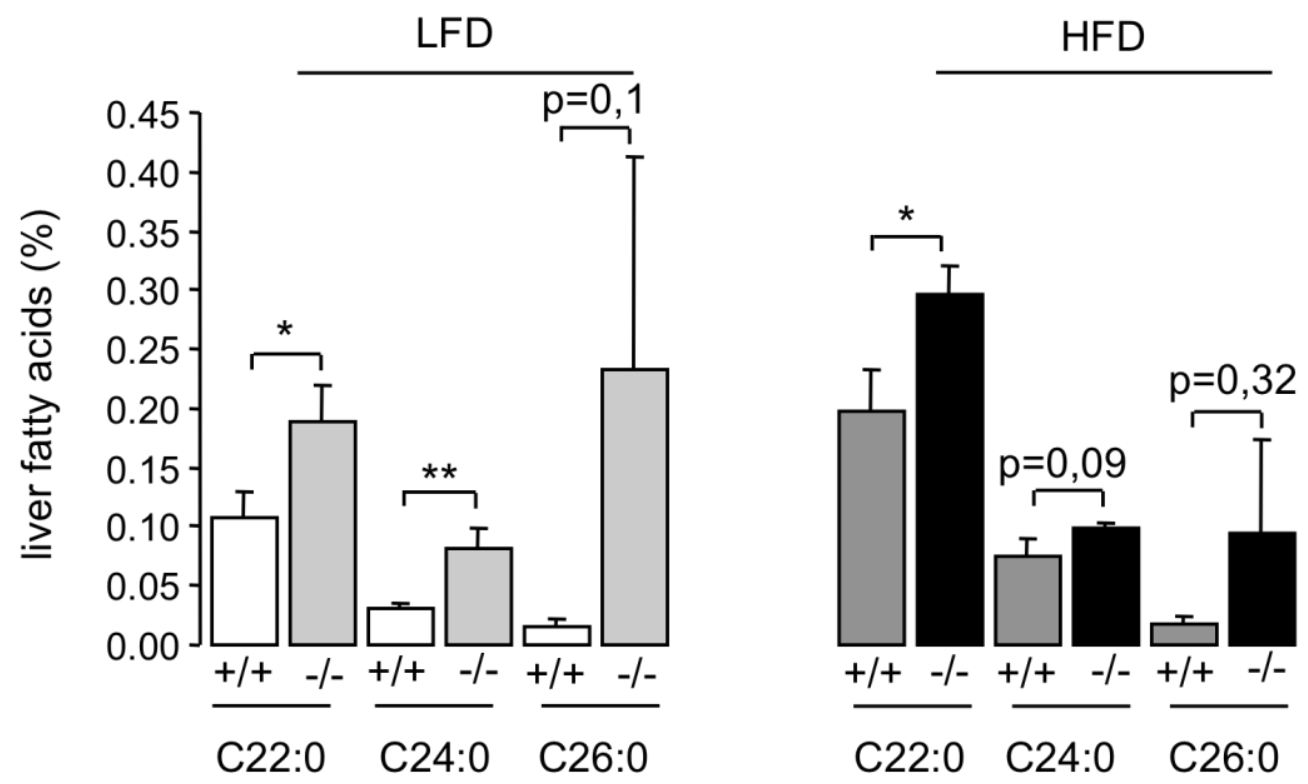

Nicolas-Francès et al., supplemental Fig. 2 